Capítulo VII

\title{
Metodología, resultados y discusión basado en el estudio "Caracterización y localización de las personas en situación de discapacidad en el distrito de Barranquilla"
}

Yaneth Herazo Beltrán • Yisel Pinillos Patiño • José Armando Vidarte Claros 


\section{METODOLOGÍA DEL ESTUDIO}

\section{Tipo de Estudio, muestreo e instrumento para la recolección de la información}

En este capítulo se presenta un análisis de los resultados de un estudio realizado bajo el paradigma empírico-analítico, en una investigación epidemiológica de tipo analítico transversal de base poblacional que buscó caracterizar a las personas con discapacidad en la ciudad de Barranquilla. Se analizan las variables tenidas en cuenta para establecer la línea de base de la discapacidad para el distrito de Barranquilla: características sociodemográficas, origen de la discapacidad, participación en actividades familiares y comunitarias de las personas con discapacidad, trabajo y educación.

Para tal fin se utilizaron como unidades de observación las localidades del distrito de Barranquilla, georreferenciadas por la Secretaría de Planeación Distrital en cinco localidades: Norte Centro Histórico, Riomar, Sur Occidente, Metropolitana, Sur Oriente. En cada localidad se realizó la búsqueda activa de las personas con discapacidad a través de la difusión por medios masivos, y con la participación de profesores y estudiantes del Programa de Fisioterapia de la Universidad Simón Bolívar, los líderes comunitarios, las Juntas de Acción Comunal, los Comités de Participación Comunitaria, los Pasos y Caminos y organizaciones de las personas con discapacidad.

Para la recolección de la información se aplicó el instrumento Registro para la Localización y Caracterización de Personas con Discapacidad del Departamento Administrativo Nacional de Estadística del Ministerio de Salud y Protección Social, previo a ello se buscó la firma del consentimiento informado por parte de cada una de las personas que participarían, además de contar con la aprobación del Comité de Ética de la Universidad 
Simón Bolívar. Este instrumento indagó sobre: condiciones de localización y vivienda, identificación personal, caracterización y origen de la discapacidad, salud, educación, participación en actividades familiares o comunitarias y trabajo de las personas con discapacidad.

Este trabajo de investigación se acogió a los lineamientos éticos emanados por el Ministerio de Salud según Resolución 008430 de 1993, Artículo 11, por las cuales se establecen las normas científicas, técnicas y administrativas para la investigación de salud en Colombia. Con base en la anterior resolución, esta investigación se categorizó sin riesgo por cuanto es un estudio que emplea técnicas y métodos de investigación documental y no se realizó ninguna intervención o modificación intencionada de las variables biológicas, fisiológicas, sicológicas o sociales de los individuos que participaron en el estudio; solo se consideró la aplicación de cuestionarios, los cuales no buscaron identificar aspectos sensitivos de la conducta de las personas.

Mediante un muestreo no probabilístico en cadena (bola de nieve) se localizó e identificó a 4.040 personas con discapacidad, distribuidas en cada una de las localidades en que se encuentra organizada la ciudad. Para ello se identificó cada una de las cinco localidades mencionadas, seguidamente se tuvieron en cuenta las calles de cada una de estas localidades y las viviendas ubicadas en dichas calles; de esta manera se realizó una búsqueda casa a casa, teniendo en cuenta para la organización del recorrido, las viviendas, zonas o familias asignadas a cada uno de los "caminantes de la salud" como son denominados en el modelo de salud de Barranquilla los promotores de salud.

La investigación se llevó a cabo teniendo en cuenta las siguientes fases: 


\section{Fase 1. Socialización del Proyecto}

Para tal fin se convocó a los Directivos de la Secretaría Distrital de Salud (Equipo de Enfermedades Crónicas No Transmisibles y Equipo de Vigilancia Epidemiológica) y a la Dirección de Investigación de la Universidad Simón Bolívar con el propósito de presentarles la propuesta de trabajo.

Durante esta fase, se desarrolló el proceso de capacitación de los encuestadores, en la cual los investigadores (docentes del Programa de Fisioterapia y miembros del Grupo Muévete Caribe de la Universidad Simón Bolívar), con la orientación del Ministerio de la Protección Social, entrenaron a estudiantes del Programa de Fisioterapia de la mencionada institución de educación superior y a profesionales del área de la salud quienes se desempeñan como "Caminantes de la Salud" y forman parte del Programa de Enfermedades Crónicas No Transmisibles y del Equipo de Vigilancia Epidemiológica de la Secretaría de Salud Distrital deBarranquilla. Todo el personal fue capacitado en el manejo y diligenciamiento de la encuesta Registro para la Localización y Caracterización de Personas con Discapacidad.

\section{Fase 2. Acercamiento a la población de estudio}

De acuerdo con la identificación de las áreas dispuestas a recorrer en cada una de las localidades, según asignación previa a cada Caminante de la Salud del Distrito, se realizó la búsqueda y diligenciamiento puerta a puerta del consentimiento informado en el cual se les explicaron los objetivos del estudio, en qué consistía su participación, y el formulario encuesta Registro para la Localización y Caracterización de Personas con Discapacidad, determinado en la investigación como el instrumento para la recolección de la información correspondiente. 


\section{Fase 3. Digitación, procesamiento y análisis de la información}

Se utilizó el programa Excel para el proceso de digitación de la información recogida mediante el Instrumento definido por el DANE para tal fin, y el programa SPSS versión 18.0 (Licencia $\mathrm{N}^{\circ} 10138194$ ) para procesar y analizar la información recogida.

\section{RESULTADOS Y DISCUSIÓN DE LOS DATOS DEL ESTUDIO}

La prevalencia de personas con discapacidad en el mundo va en aumento, dado al proceso de envejecimiento poblacional en que se encuentran las regiones; por ese motivo, los años de vida han aumentado y con ello el riesgo de adquirir una discapacidad en edades avanzadas, ya sea como secuela de cualquier enfermedad o por el deterioro progresivo de las capacidades funcionales en el ser humano en la medida que se envejece; además de los accidentes de cualquier tipología, los conflictos armados en los cuales se ha visto envuelta nuestra población tanto en zonas rurales como urbanas, la violencia y el uso abusivo de drogas y alcohol; los desastres naturales, la desnutrición, la marginalización de los diferentes grupos sociales y la pobreza extrema.

Conocer las condiciones demográficas de una población permite no solo saber su estado en cuanto a estructura y dinámica sino que favorece las proyecciones que en materia de aspectos sociales, culturales, educativos, políticos, en salud y económicos se puedan generar (1). En este sentido, el presente estudio permite identificar y analizar la situación actual en el distrito de Barranquilla, la cual se presenta a continuación:

\section{Análisis y distribución de la población registrada según características sociodemográficas}

De acuerdo con el análisis estadístico realizado, se observó que del total 
de personas con discapacidad encuestadas 75,2 \% reside en el área de la cabecera, 22,5\% en centro poblado y 2,3\% en rural disperso. El 45,6 \% de las personas con discapacidad reside en la localidad del Sur Occidente de Barranquilla; 26,4 \% en la localidad Metropolitana; 20,9 \% residen en el Sur Oriente; 3,8 \% en el Norte Centro Histórico y 3,3 \% en Riomar. El $61,9 \%$ de las personas encuestadas con discapacidad pertenecen al estrato socioeconómico $1 ; 20,5 \%$ pertenece al estrato $2 ; 16,6 \%$ al estrato socioeconómico 3 y solo el $0,9 \%$ pertenece a los estratos 4,5 y 6 .

\section{Tabla 1}

Distribución de la población registrada según el tipo de área, localidad y estrato socioeconómico de la residencia

\begin{tabular}{|c|c|c}
\hline Área & Frecuencia & Porcentaje \\
\hline Cabecera & 3040 & 75,2 \\
\hline Centro Poblado & 910 & 22,5 \\
\hline Rural Disperso & 94 & 2,3 \\
\hline Localidad & & \\
\hline Metropolitana & 1067 & 26,4 \\
\hline Norte Centro Histórico & 155 & 3,8 \\
\hline Riomar & 133 & 3,3 \\
\hline Sur Oriente & 845 & 20,9 \\
\hline Suroccidente & 1844 & 45,6 \\
\hline Estrato & & 61,9 \\
\hline Estrato 1 & 2503 & 20,5 \\
\hline Estrato 2 & 828 & 16,6 \\
\hline Estrato 3 & 671 & 0,8 \\
\hline Estrato 4 & 32 & 0,1 \\
\hline Estrato 5 & 5 & 0,02 \\
\hline Estrato 6 & 1 & 0,1 \\
\hline No sabe & 4 & \\
\hline
\end{tabular}

De acuerdo con la distribución por sexo, se evidenció que el 55,9\% de las personas con discapacidad encuestadas son hombres y el $44,1 \%$ son mujeres. El 7,9 \% de los encuestados tiene entre 30-34 años de edad; 7,6 \% tiene más de 80 años de edad; 7,2 \% tienen entre 40-44 años de edad; 7,0 \% se encuen- 
tra en edades entre 15-19 años; 7,0 \% entre 45-49 años; el 6,7 \% tiene entre 25-29 años de edad; 6,6 \% tiene entre 20-24 años y el $6 \%$ se encuentra en edades entre 55-59 años. De las personas registradas según las costumbres y tradiciones $90,9 \%$ se considera mestizo u otro diferente; $6,6 \%$ se consideran negro afrodescendiente y $1,9 \%$ se considera raizal del archipiélago.

\section{Tabla 2}

Distribución de la población según el sexo, rango de edad

\begin{tabular}{|c|c|c|}
\hline Sexo & Frecuencia & Porcentaje \\
\hline Hombre & 2261 & 55,9 \\
\hline Mujer & 1783 & 44,1 \\
\hline \multicolumn{3}{|l|}{ Edad } \\
\hline 0-4 años & 140 & 3,5 \\
\hline 5-9 años & 191 & 4,7 \\
\hline 10-14 años & 254 & 6,3 \\
\hline 15-19 años & 285 & 7,0 \\
\hline 20-24 años & 265 & 6,6 \\
\hline 25-29 años & 270 & 6,7 \\
\hline 30-34 años & 321 & 7,9 \\
\hline 35-39 años & 251 & 6,2 \\
\hline 40-44 años & 292 & 7,2 \\
\hline 45-49 años & 284 & 7,0 \\
\hline 50-54 años & 240 & 5,9 \\
\hline 55-59 años & 242 & 6,0 \\
\hline 60-64 años & 208 & 5,1 \\
\hline 65-69 años & 146 & 3,6 \\
\hline 70-74 años & 184 & 4,5 \\
\hline 75-79 años & 163 & 4,0 \\
\hline Más de 80 años & 308 & 7,6 \\
\hline \multicolumn{3}{|l|}{ Etnia } \\
\hline Negro afrodescendiente & 266 & 6,6 \\
\hline Raizal del archipiélago & 77 & 1,9 \\
\hline Palanquero & 10 & 0,2 \\
\hline Gitano(a) ROM (Li) & 1 & 0,0 \\
\hline Indígena & 16 & 0,4 \\
\hline Mestizo u otro diferente & 3674 & 90,9 \\
\hline
\end{tabular}


Los hallazgos del presente estudio correspondientes a las características sociodemográficas de los participantes, se correlacionan con lo descrito por Neves y Álvarez, quienes al realizar un estudio descriptivo mediante el análisis de datos secundarios de encuestas de discapacidad en América Latina entre 2001 y 2009 encontraron que la discapacidad en los países latinoamericanos (Ecuador, El Salvador, Guatemala, Honduras y República Dominicana) es más prevalente en el área rural; entre tanto que en Argentina, Brasil, Chile, Nicaragua y Uruguay es mayor la prevalencia en el área urbana, lo cual es equivalente a los hallazgos del presente estudio (2).

Con relación a la clase social estipulada como un determinante estructural, los datos del presente estudio se correlacionan con los hallazgos reportados en Colombia en 2005 y 2011, donde el estrato socioeconómico 1 fue donde mayormente se encontró ubicada la población caracterizada, seguida de los estratos 2 y 3 alcanzando el $94 \%$ de la población total identificada mientras que los estratos altos no alcanzan a superar el $6 \%$ (3).

Este mismo estudio identifica que los hombres fueron más afectados en un $66,7 \%$ por la discapacidad en relación con el grupo de las mujeres. Solo en países como Argentina, Brasil, Chile, Nicaragua y Uruguay se observa mayor prevalencia de discapacidad en el grupo de las mujeres. Con relación a la edad se evidencia que el $75 \%$ de los países reporta discapacidad con mayor frecuencia en las personas mayores de 65 años; solamente Chile y Guatemala reportaron prevalencia en personas con edades inferiores a esta, resultado que tiene relación con lo encontrado en el presente estudio. Solamente difiere en que en el distrito de Barranquilla hay una frecuencia levemente elevada de las personas con discapacidad con edades entre 30-34 años.

Sin embargo esta es seguida por la edad superior a 80 años; en este sentido, se comprueba la relación directa que hay entre vejez y discapacidad lo cual ha sido identificado por otros autores como Neves y Álvarez; al igual que lo demuestra el informe de la Organización Panamericana de la Salud, donde se afirma que el riesgo de discapacidad aumenta en la medida en que es mayor la edad de la persona, y estas tasas de discapacidad en adultos 
mayores son el reflejo de la acumulación de los riesgos en salud durante la vida y es más alta en mayores de 45 años de edad en países de bajos ingresos (4).

A diferencia de lo evidenciado por el Registro para la Localización y Caracterización de Personas con Discapacidad (RLCPD) sobre datos de etnicidad en Barranquilla, en el último registro de 2005 el 46,4 \% se identificó en algún grupo étnico y en 2011, se registró $41,5 \%$, de estos. El grupo de otras etnias y los indígenas fueron los grupos con mayores registros de personas con discapacidad (3).

Tabla 3

Frecuencia de los servicios públicos con los que cuentan las viviendas de las personas con discapacidad

\begin{tabular}{|l|c|c|}
\hline \multicolumn{1}{|c|}{ Descripción } & Frecuencia & Porcentaje \\
\hline Servicios públicos & & \\
\cline { 2 - 3 } Energía eléctrica & 3962 & 98 \\
\hline Alcantarillado & 3734 & 92,3 \\
Gas natural & 3611 & 89,3 \\
\hline Teléfono & 1471 & 36,4 \\
\hline Recolección de basuras & 3577 & 88,5 \\
\hline Acueducto & 3653 & 90,3 \\
\hline Ninguno & 108 & 2,7 \\
\hline Agua potable & & \\
\hline Sí & 3793 & 93,8 \\
\hline No & 86 & 2,1 \\
\hline No responde & 165 & 4,1 \\
\hline Tipo de vivienda & & \\
\hline Casa & 2983 & 73,8 \\
\hline Apartamento & 733 & 18,1 \\
\hline Cuarto & 221 & 5,5 \\
\hline Institución pública & 7 & 0,2 \\
\hline Institución privada & 2 & 0,0 \\
\hline Calle & 3 & 0,1 \\
\hline Otro tipo de vivienda & 99 & 2,3 \\
\hline Condición de la vivienda & & \\
\hline Arriendo o subarriendo & 1900 & 43,2 \\
\hline Vivienda propia y la está pagando & 1067 & 26,4 \\
\hline Vivienda propia totalmente pagada & 92 & 2,3 \\
\hline Vivienda de un familiar sí paga arriendo & 119 & 3,0 \\
\hline Vivienda de un tercero sin pagar arriendo & & \\
\hline Otra & 351 & \\
\hline & & \\
\hline
\end{tabular}


El análisis de los resultados también permitió identificar que el $98 \%$ de las personas encuestadas cuenta en su residencia con energía eléctrica; 90,3\% con acueducto; 92,3\% con alcantarillado; $89,3 \%$ con gas natural; 88,5 \% con recolección de basuras y el $36,4 \%$ con teléfono; solamente el $2,7 \%$ no cuenta con ningún servicio.

De las personas con discapacidad registradas $93,8 \%$ cuenta con agua potable para la preparación de los alimentos y solo el 2,1\% no cuenta con este recurso. El 73,8 \% reside en casa; $18,1 \%$ vive en apartamento y 5,5\% vive en cuartos; el 2,3\% vive en otro tipo de vivienda. El $47 \%$ reside en una vivienda propia totalmente pagada; $26,4 \%$ en una vivienda familiar sin pagar arriendo; $13,2 \%$ vive en arriendo o subarriendo; $8,2 \%$ en vivienda propia y la está pagando; $2,3 \%$ vive en la casa de una tercera persona sin pagar arriendo y $3 \%$ tiene otra condición de tenencia de la vivienda donde residen.

En este sentido, sobre las condiciones de la vivienda de las personas con discapacidad, la evidencia permite identificar la importante influencia que tiene el ambiente en la salud de esta población en particular, e inferir además que el ambiente puede generar discapacidad en la persona que tiene una condición de salud o quien posee una deficiencia (4).

Los datos de este estudio con respecto a la frecuencia de los servicios públicos con los que cuentan las viviendas de las personas con discapacidad, se correlacionan con lo descrito en el informe del último censo realizado en el país en donde se observó que el acceso a estos servicios básicos en las PCD en comparación con la población en general era de 79,87 \% frente a $83,44 \%$, el acceso a la luz eléctrica del $92,6 \%$ frente a $93,5 \%$ y alcantarillado $65,32 \%$ frente al 73,08 \%, lo cual expresa claramente el bajo nivel de servicios básicos con que esta población de estudio cuenta en Colombia (5). 
Metodología, resultados y discusión basado en el estudio "Caracterización y localización de las personas en situación de discapacidad en el distrito de Barranquilla"

Tabla 4

Distribución de la población registrada según con quien vive actualmente

\begin{tabular}{|c|c|c|}
\hline Descripción & Frecuencia & Porcentaje \\
\hline \multicolumn{3}{|l|}{ Actualmente vive } \\
\hline Solo & 143 & 3,5 \\
\hline Acompañado & 3901 & 96,5 \\
\hline \multicolumn{3}{|c|}{ Cuántas personas conforman la familia } \\
\hline 0 a 3 personas & 994 & 24,6 \\
\hline 4 a 6 personas & 1939 & 47,9 \\
\hline 7 a 10 personas & 899 & 22,2 \\
\hline 11 a 15 personas & 192 & 4,7 \\
\hline Más de 16 personas & 20 & 0,5 \\
\hline \multicolumn{3}{|c|}{ Número de personas con discapacidad } \\
\hline 1 persona & 3129 & 77,4 \\
\hline 2 personas & 745 & 18,4 \\
\hline 3 personas & 131 & 3,2 \\
\hline 4 personas & 39 & 1,0 \\
\hline \multicolumn{3}{|l|}{ Personas a cargo } \\
\hline Sí & 791 & 19,6 \\
\hline No & 3253 & 80,4 \\
\hline \multicolumn{3}{|c|}{ Número de personas menores de 12 años } \\
\hline 0 a 3 personas & 4005 & 99,0 \\
\hline 4 a 6 personas & 34 & 0,8 \\
\hline Más de 7 personas & 5 & 0,2 \\
\hline \multicolumn{3}{|c|}{ Número de personas mayores de 60 años } \\
\hline Ninguna & 3708 & 91,7 \\
\hline 1 persona & 256 & 6,3 \\
\hline 2 personas & 76 & 1,9 \\
\hline 3 personas & 3 & 0,1 \\
\hline 4 personas & 1 & 0,0 \\
\hline Total & 4044 & 100,0 \\
\hline
\end{tabular}

El 96,5 \% de las personas registradas con discapacidad residen acompañados y el $3,5 \%$ vive solo.

El 47,9 \% de las personas registradas reside en un hogar conformado por 4 a 6 personas; 24,6 \% en un hogar conformado por 3 personas; $22,2 \%$ 
reside en un hogar conformado por 7 a 10 personas y el 4,7 \% en un hogar conformado por 11 y 15 personas. De acuerdo con el registro se encontró que del total de personas que conforman el hogar en el 77,4 \% de los casos en el grupo hay 1 persona con discapacidad; en el 18,4\% el grupo familiar cuenta con 2 personas con algún tipo de discapacidad y en el 3,2\% de los casos el grupo cuenta con 3 personas con discapacidad.

El 80,4\% de las personas registradas con discapacidad no tiene a cargo otra persona, mientras que el 19,6\% sí lo tienen. E1 99 \% de las personas registradas tiene a cargo 3 personas menores de 12 años de edad y el $8 \%$ tiene de 4 a 6 personas de estas mismas características a cargo. De los encuestados $91,7 \%$ no tiene a ninguna persona mayor de 60 años de edad a su cargo; $6,3 \%$ tiene a una persona mayor de 60 años de edad a su cargo y solo el $1,9 \%$ de los registrados tiene 2 personas con estas mismas características a su cargo.

Con relación a este aspecto, es evidente que son diversas las complejidades a las cuales deben enfrentarse las familias cuando a uno de sus miembros llega la discapacidad, ya que todo el entorno es afectado; sin embargo la inclusión de ellas al seno de la familia permite afrontar la situación (6).

Los resultados de este estudio, se corresponden con la situación evidenciada en el último censo a nivel nacional donde llamó la atención que el 7 \% de las personas que fueron incluidas en el Registro para la Localización y Caracterización de Personas con Discapacidad (RLCPD) viven solas y un porcentaje menor del $18 \%$ tienen personas a cargo (7).

Sin embargo, un estudio realizado en Santiago de Cali, confirmó que del total de los encuestados, el $50 \%$ percibía ingresos mensuales de hasta de un salario mínimo y el 60 \% tenía personas a cargo, siendo responsable del sostenimiento económico por lo menos de una persona, lo cual contrasta con lo hallado en el presente estudio (8). 


\section{Tabla 5}

Distribución de la población registrada según si recibe algún servicio del Instituto Colombiano de Bienestar Familiar

\begin{tabular}{|l|c|c|}
\hline \multicolumn{1}{|c|}{ Descripción } & Frecuencia & Porcentaje \\
\hline Recibe algún beneficio & & \\
\cline { 2 - 3 } $\mathrm{Si}$ & 168 & 4,2 \\
\hline $\mathrm{No}$ & 3876 & 95,8 \\
\hline Tipo de Programas & & \\
\hline Protección & 50 & 1,2 \\
\hline Hogar sustituto & 13 &, 3 \\
\hline Hogar comunitario & 40 & 1,0 \\
\hline Hogar infantil & 16 &, 4 \\
\hline Club juvenil & 7 &, 2 \\
\hline Otro programa de bienestar & 162 & 4,0 \\
\hline Ninguno & 3756 & 92,8 \\
\hline Total & 4044 & 100 \\
\hline
\end{tabular}

La Tabla 5 muestra que el 95,8 \% de las personas registradas no recibe algún servicio del Instituto Colombiano de Bienestar Familiar; solo el 4,2 \% sí lo recibe. El 92,8 \% de las personas registradas no son beneficiarios de programas; el $0,4 \%$ es beneficiario de un programa de bienestar y el $1,2 \%$ recibe protección; solo el $4 \%$ son beneficiarios de otro programa de bienestar.

Teniendo en cuenta que en Colombia la discapcidad tiene relación con la situación a nivel mundial, el apoyo social que reciba la persona con discapacidad tiene un factor importante en la determinación de su autoestima; en este sentido, un estudio realizado en 30 personas de ambos sexos, mayores de edad, con discapacidad física y adscritos a una asociación en el municipio de Tuluá en Colombia permitió evidenciar que el apoyo social es favorable para las personas en esta condición; así, la construcción social percibida a partir de la discapacidad es positiva y las personas que la enfrentan, están observando mejor calidad de vida que lo que ellos mismos esperaban tener (9). 


\section{CARACTERIZACIÓN Y ORIGEN DE LA DISCAPACIDAD}

\section{Tabla 6}

Distribución de la población registrada según las alteraciones permanentes presentes

\begin{tabular}{|l|c|c|}
\hline \multirow{2}{*}{ Alteraciones permanentes } & \multicolumn{2}{c}{ Sí } \\
\cline { 2 - 3 } & Frecuencia & Porcentaje \\
\hline El sistema nervioso & 2404 & 59,4 \\
\hline Los ojos & 3081 & 76,2 \\
\hline Los oídos & 3446 & 85,2 \\
\hline Los demás órganos de los sentidos (olfato, tacto y & 3904 & 96,5 \\
gusto) & 2636 & 65,2 \\
\hline La voz y el habla & 3682 & 91,0 \\
\hline El sistema cardiorrespiratorio y las defensas & 3814 & 94,3 \\
\hline La digestión, el metabolismo, las hormonas & 3885 & 96,1 \\
\hline El sistema genital y reproductivo & 1930 & 47,7 \\
\hline El movimiento del cuerpo, manos, brazos, piernas & 3876 & 95,8 \\
\hline La piel & & \\
\hline
\end{tabular}

El 96,5\% de las personas presenta alteraciones permanentes de los órganos de los sentidos (olfato, tacto y gusto); 96,1\% del sistema genital y reproductivo; $95,8 \%$ de la piel; 94,3 \% de la digestión, el metabolismo y las hormonas; $85,2 \%$ de los oídos; 76,2 \% de los ojos; de la voz y el habla $65,2 \%$; del sistema nervioso $59,4 \%$ y $47,7 \%$ presenta alteraciones permanentes del movimiento del cuerpo, manos, brazos, piernas.

\section{Tabla 7}

Distribución de la población registrada según las dificultades permanentes que presenta en su vida diaria

\begin{tabular}{l|c|c}
\hline \multirow{2}{*}{ Dificultades permanentes } & \multicolumn{2}{c}{ Sí presentan dificultades } \\
\cline { 2 - 3 } & Frecuencia & Porcentaje \\
\hline Pensar, memorizar & 2640 & 65,3 \\
Percibir la luz, distinguir objetos o personas a pesar de usar lentes o & 3457 & 85,5 \\
gafas & 3709 & 91,7 \\
Oír, aun con aparatos especiales & 3905 & 96,6 \\
Distinguir sabores u olores & 2631 & 65,1 \\
\hline Hablar y comunicarse &
\end{tabular}




\begin{tabular}{l|c|c}
\hline \multirow{2}{*}{ Dificultades permanentes } & \multicolumn{2}{c}{ Sí presentan dificultades } \\
\cline { 2 - 3 } & Frecuencia & Porcentaje \\
\hline $\begin{array}{l}\text { Desplazarse en trechos cortos por problemas respiratorios o del } \\
\text { corazón }\end{array}$ & 3643 & 90,1 \\
Masticar, tragar, asimilar y transformar los alimentos & 3769 & 93,2 \\
\hline Retener o expulsar la orina, tener relaciones sexuales, tener hijos & 3687 & 91,2 \\
Caminar, correr, saltar & 2085 & 51,6 \\
Mantener piel, uñas y cabellos sanos & 3837 & 94,9 \\
Relacionarse con las demás personas y el entorno & 3467 & 85,7 \\
\hline Llevar, mover, utilizar objetos con las manos & 3351 & 82,9 \\
Cambiar y mantener las posiciones del cuerpo & 3333 & 82,4 \\
\hline Alimentarse, asearse y vestirse por sí mismo & 3266 & 80,8 \\
\hline Otra & 3898 & 96,4 \\
\hline
\end{tabular}

De acuerdo con los registros se observa que $96,6 \%$ presenta dificultades permanentes para distinguir sabores u olores en su vida diaria; $96,4 \%$ presenta otra dificultad permanente diferente a la del listado de la encuesta; 94,9\% para mantener piel, uñas y cabellos sanos; 93,2 \% para masticar, tragar, asimilar y transformar los alimentos; $91,7 \%$ dice que su dificultad permanente en la vida diaria es para oír, aun con aparatos especiales; $91,2 \%$ para retener o expulsar la orina, tener relaciones sexuales, tener hijos; 90,1\% para desplazarse en trechos cortos por problemas respiratorios o del corazón; 85,7 \% para relacionarse con las demás personas y el entorno; 85,5\% para percibir la luz, distinguir objetos o personas a pesar de usar lentes o gafas; 82,9 \% para llevar, mover, utilizar objetos con las manos; $82,4 \%$ para cambiar y mantener las posiciones del cuerpo; 80,8 \% para alimentarse, asearse y vestirse por sí mismo; $65,3 \%$ para pensar, memorizar; $65,1 \%$ para hablar y comunicarse y $51,6 \%$ para caminar, correr, saltar.

Vélez y cols en su estudio realizado en Santiago de Cali, en 38.071 personas con discapacidad identificadas en el registro del DANE para la Localización y Caracterización de Personas con Discapacidad de esta región 
del país en el año 2011, observaron que las deficiencias relacionadas con el sistema nervioso, ojos, el sistema cardiorrespiratorio y de defensas fueron las más frecuentes alteraciones permanentes; con relación a las dificultades permanente, identificaron que la de mayor procentaje era la limitación para caminar, correr y saltar; así, el $100 \%$ de la población con discapacidad identificada en la ciudad tiene una deficiencia en el funcionamiento de uno de los sistemas y una limitación permamente (10).

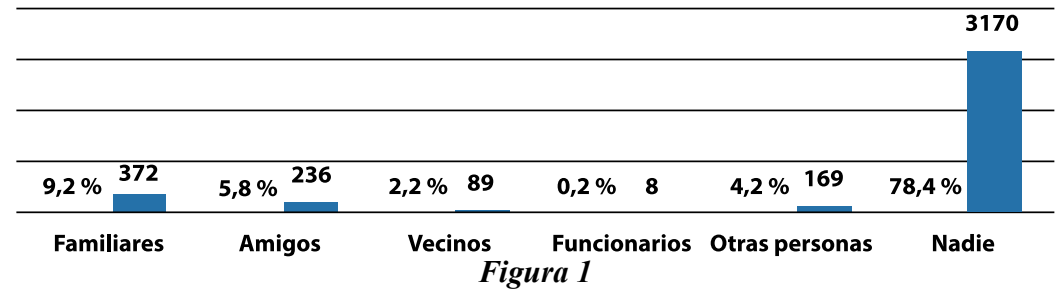

Distribución de la población registrada según quiénes presentan actitudes negativas que le impiden desarrollar su actividad diaria con mayor autonomía

La Figura 1 muestra que aunque un 78,4 \% de las personas registradas afirma que nadie presenta una actitud negativa que le impida a la persona con discapacidad desarrollar su actividad diaria con mayor autonomía, el 9,2 \% dice que los familiares; el 5,8 \% dice que sus amigos, compañeros; $2,2 \%$ dice que sus vecinos; el 4,2 \% dice que otras personas; $0,2 \%$ expresa que los funcionarios y empleados tienen una actitud negativa hacia ellos.

Es evidente que entre los factores que obstaculizan la participación y el desarrollo de las personas con discapacidad se encuentran los aspectos relacionados con las actitudes de la población, los sistemas, servicios y políticas frente a este tema; los resultados de la presente investigación se correlacionan con otros trabajos que han permitido - mediante metodología cualitativa- explorar los sentimientos y reacciones de los padres con hijos con Síndrome de Down (SD) en Ecuador, observándose que a pesar de que existe una respuesta de adaptación de los padres y de las familias, persisten las actitudes negativas con respecto a las personas con este tipo de discapacidad en particular (11). 
En este sentido, son diversos los estudios de investigación respecto a las actitudes hacia las personas con discapacidad en diferentes colectivos sociales: profesores, profesionales de la salud o compañeros de clase. Aunque la actitud encontrada hacia las personas con discapacidad en una muestra de 260 estudiantes de una universidad pública de la ciudad de La Serena, Chile, fue positiva, se resalta una predisposición en dichos sujetos, favorable para actuar y aceptar de manera efectiva a las personas con discapacidad en contextos sociales, laborales y personales, reconocen además los derechos de estas personas con relación a la accesibilidad y participación en actividades cívicas, laborales, ocio, entre otros contextos (12).

\section{Tabla 8}

Distribución de la población registrada según en qué lugares de su vivienda o entorno físico, encuentra barreras que le impiden desarrollar sus actividades diarias con mayor autonomía

\begin{tabular}{l|c|c}
\hline \multirow{2}{*}{ Barreras que impiden desarrollar las actividades diarias } & \multicolumn{2}{|c}{ Sí } \\
\cline { 2 - 3 } & Frecuencia & Porcentaje \\
\hline Dormitorio & 3615 & 89,4 \\
\hline Sala-comedor & 3683 & 91,1 \\
\hline Baño-sanitario & 3176 & 78,5 \\
\hline Escaleras & 3254 & 80,5 \\
\hline Pasillos-patios & 3596 & 88,9 \\
\hline Andenes, aceras & 3444 & 85,2 \\
\hline Calles, vías & 2873 & 71,0 \\
Parques, plazas, estadios, teatros, iglesias & 3497 & 86,5 \\
\hline Paraderos, terminales de transporte & 3555 & 87,9 \\
\hline Vehículos de transporte público & 3227 & 79,8 \\
\hline Centros educativos & 3797 & 93,9 \\
\hline Lugares de trabajo & 3871 & 95,7 \\
\hline Centros de salud, hospitales & 3636 & 89,9 \\
\hline Centros comerciales, tiendas, plazas de mercado & 3534 & 87,4 \\
\hline Otros lugares & 3810 & 94,2 \\
\hline
\end{tabular}


De acuerdo con el registro se observa que el 95,7\% encuentra barreras en su lugar de trabajo que le impide desarrollar sus actividades diarias con mayor autonomía; 94,2\% dice que en otros lugares diferentes a los del listado de la encuesta; 93,9\% afirma que en los centros educativos; $91,1 \%$ en la sala-comedor; $89,9 \%$ en los centros de salud, hospitales; $89,4 \%$ en el dormitorio; $88,9 \%$ en los pasillos-patios; $87,9 \%$ en los paraderos, terminales de transporte; $87,4 \%$ en los centros comerciales, tiendas, plazas de mercado; $86,5 \%$ en parques, plazas, estadios, teatros, iglesias; $85,2 \%$ andenes-aceras; $80,5 \%$ escaleras; $79,8 \%$ en vehículos de transporte público; $78,5 \%$ en baño-sanitario; $71 \%$ en calles, vías.

El ambiente en el que viven y se desarrollan las personas tiene efecto en la prevalencia y magnitud con que se presente la discapacidad; por tal motivo los cambios estructurales y arquitectónicos que se generen inciden en esta prevalencia ya que se presentan como un factor que limita el libre desplazamiento en el entorno físico. Con relación a este aspecto se comprende que los factores ambientales influyen de manera positiva o negativa en la participación de las personas con discapacidad, entre las cuales se encuentran las relacionadas con barreras arquitectónicas de la comunidad o del hogar (13).

Con relación a estas barreras, lo encontrado en este estudio se puede comparar con lo descrito por Hurtado en un estudio realizado en 45 adultos con discapacidad motriz de miembros inferiores en la ciudad de Santiago de Cali (Colombia), donde el $98 \%$ de los encuestados indicó que había andes circundantes con una amplitud de 0,80 metros pero el $19 \%$ percibe que son menores de esta medida; así mismo el $75 \%$ reportó la existencia de algún tipo de desnivel u obstáculo en las aceras y un $16 \%$ expresó que solo podían transitar por la vía dado que estas aceras eran intransitables para su condición. Por otra parte, un $54 \%$ consideró que en los edificios públicos se encuentran las principales barreras del entorno (8). 
Este mismo estudio permitió confirmar que las personas con discapacidad percibe que tienen limitaciones para desplazarse en el transporte público como pasajeros en un $62 \%$ y en un $30 \%$ al conducir un vehículo adaptado. Existe entonces una necesidad por parte de las PCD de desplazarse con mayor facilidad en las casas, edificios públicos, privados, otras viviendas, calles, parques, avenidas y carreteras, lo cual se hizo evidente en los residentes encuestados en Cali (56\%).

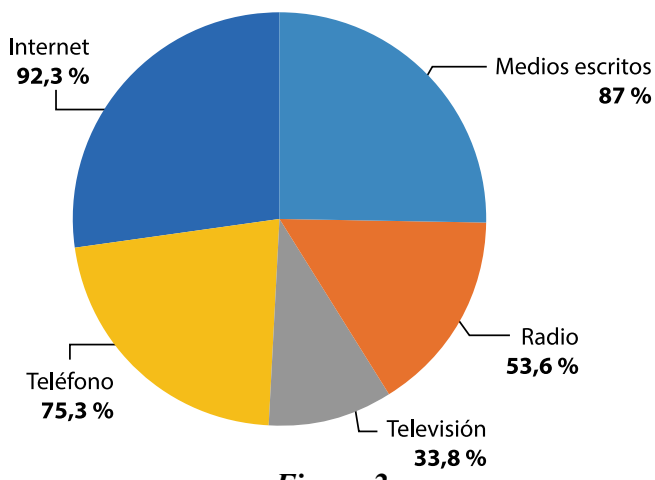

Figura 2

Distribución de la población registrada según los medios de comunicación que utiliza actualmente

El 92,3 \% (3731) de la población con discapacidad registrada en el informe utiliza el Internet; 87 \% (3520) dice utilizar los medios de comunicación escritos; 75,3\% (3046) utiliza el teléfono; 53,6 \% (2166) la radio; 33,8 \% (1368) la televisión. Estos resultados se correlacionan con el uso reportado por 870 hombres y mujeres con discapacidad visual de la provincia de Tungurahua, Ecuador, y 325 estudiantes de la carrera de Comunicación Social de la Universidad Técnica de Ambato del país en mención, quienes utilizan con mayor frecuencia el computador con características específicas para su tipo de discapacidad y los medios masivos de comunicación e información más usados son las páginas web, prensa, libros y revistas digitales; las redes sociales también evidenciaron un frecuente uso, lo cual contribuye a la accesibilidad a la información de las personas (14). 


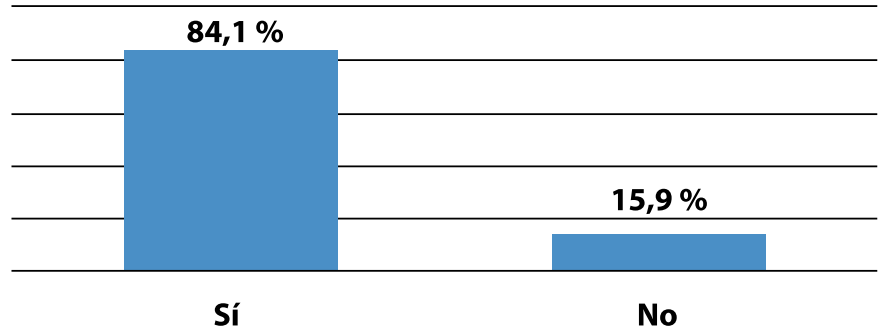

Figura 3

Distribución de la población registrada según conocimiento del origen de la discapacidad

El 84,1 \% (3.400 personas) de la población registrada y que se encuentra en situación de discapacidad afirma que sí conoce el origen de esta; mientras que el 15,9\% (644) dice no conocerla.

\section{Tabla 9}

Distribución de la población registrada según la consecuencia principal de la discapacidad

\begin{tabular}{l|c|c}
\hline \multicolumn{1}{c|}{ Consecuencia de la discapacidad } & Frecuencia & Porcentaje \\
\hline Condiciones de salud de la madre durante el embarazo & 491 & 14,4 \\
\hline Complicaciones en el parto & 263 & 7,7 \\
\hline Enfermedad general & 1066 & 31,4 \\
\hline Alteración genética, hereditaria & 467 & 13,7 \\
\hline Lesión autoinfligida & 32 & 0,9 \\
\hline Enfermedad profesional & 80 & 2,4 \\
\hline Consumo de psicoactivos & 28 & 0,8 \\
\hline Desastre natural & 4 & 0,1 \\
\hline Accidente & 480 & 14,1 \\
\hline Víctima de violencia & 79 & 2,3 \\
\hline Conflicto armado & 319 & 9,4 \\
\hline Dificultades en la prestación de servicios de salud & 3400 & 0,4 \\
\hline Otra causa & 3,3 \\
\hline
\end{tabular}


El 31,4 \% de la población registrada con discapacidad afirma que la discapacidad que presenta es por consecuencia de una enfermedad clasificada como general; $14,4 \%$ afirma por condiciones de salud de la madre durante el embarazo; $14,1 \%$ por un accidente; $13,7 \%$ por alteración genética, hereditaria; $7,7 \%$ por complicaciones en el parto; $2,4 \%$ por enfermedad profesional, y otro $2,3 \%$ son víctimas de la violencia; $2,3 \%$ por dificultades en la prestación de servicios de salud; $9,4 \%$ por otras causas diferentes a las encontradas en el listado del registro.

Tabla 10

Distribución de la población registrada según la consecuencia principal de la discapacidad

\begin{tabular}{|c|c|c|}
\hline Consecuencia de la discapacidad & Frecuencia & Porcentaje \\
\hline \multicolumn{3}{|l|}{ Enfermedad profesional } \\
\hline Medioambiente físico del lugar de trabajo & 13 & 16,3 \\
\hline Condiciones de seguridad (máquinas, equipos, herramientas) & 11 & 13,8 \\
\hline Contaminantes (químicos, biológicos) & 1 & 1,3 \\
\hline Carga de trabajo física o mental (factores ergonómicos) & 15 & 18,8 \\
\hline Organización del trabajo (psicolaborales) & 2 & 2,5 \\
\hline Otra causa & 38 & 47,5 \\
\hline Total & 80 & 100 \\
\hline \multicolumn{3}{|l|}{ Consumo de psicoactivos } \\
\hline Psicoactivos aceptados socialmente & 8 & 28,6 \\
\hline Psicoactivos socialmente no aceptados & 20 & 71,4 \\
\hline Total & 28 & 100 \\
\hline \multicolumn{3}{|l|}{ Desastres naturales } \\
\hline Otro desastre natural & 3 & 75,0 \\
\hline Inundación & 1 & 25,0 \\
\hline Total & 4 & 100 \\
\hline \multicolumn{3}{|l|}{ Tipo de Accidente } \\
\hline De tránsito & 145 & 30,2 \\
\hline En el hogar & 174 & 36,3 \\
\hline En el centro educativo & 3 & 0,6 \\
\hline De trabajo & 71 & 14,8 \\
\hline Deportivo & 9 & 1,9 \\
\hline Otro tipo de accidente & 78 & 16,2 \\
\hline Total & 480 & 100 \\
\hline \multicolumn{3}{|l|}{ Conflicto armado } \\
\hline Arma de fuego & 8 & 61,5 \\
\hline Bomba & 1 & 7,6 \\
\hline Minas antipersonales & 3 & 23,3 \\
\hline Otro tipo de arma & 1 & 7,6 \\
\hline Total & 13 & 100 \\
\hline
\end{tabular}


El 18,8 \% de la población afirma que una enfermedad profesional generada por carga de trabajo físico o mental (factores ergonómicos) le produjo la discapacidad que hoy presenta; $16,3 \%$ por factores del medioambiente físico del lugar de trabajo; 13,8 \% por condiciones de seguridad (máquinas, equipos, herramientas); mientras que el 47,5\% dice que fue por otra causa diferente a las enlistadas en la encuesta. Solo el 2,5\% dice que por organización del trabajo (psicolaborales), y 1,3 \% por contaminantes (químicos, biológicos).

El 71,4 \% dice que la discapacidad que presenta se debe a consumo de psicoactivos socialmente no aceptados; $28,6 \%$ por consumo de psicoactivos aceptados socialmente. E1 $75 \%$ de la población dice que la discapacidad se le generó por un desastre natural, mientras que el $25 \%$ manifiesta por terremoto, inundación, deslizamiento. El 36,3 \% dice que la discapacidad que presenta se debe a un accidente en el hogar; 30,2\% por un accidente de tránsito; $14,8 \%$ por un accidente en el trabajo; $16,2 \%$ por otro tipo de accidente; $1,9 \%$ por un accidente deportivo y solo el $0,6 \%$ menciona por un accidente en el centro educativo.

El $62 \%$ dice que la discapacidad se generó por violencia de la delincuencia común; $13,9 \%$ por violencia al interior del hogar; $12,7 \%$ por violencia social; $11,4 \%$ por otro tipo de violencia. El $61,5 \%$ de las personas con discapacidad afirma que su situación actual es el resultado del conflicto armado por arma de fuego; $23,3 \%$ por minas antipersonas; un 7,6 \% por bombas y otro $7,6 \%$ por otro tipo de armas.

Con relación a la consecuencia principal que originó la discapacidad, los resultados de este estudio se pueden contrastar con un estudio realizado en Santiago de Cali, en personas mayores de edad y quienes reportaron al conflicto armado/violencia como la causa más frecuente de discapacidad representada para este grupo encuestado $42 \%$ (8). 
Por otra parte, lo hallado en la presente investigación se correlaciona con lo encontrado en un estudio en Santiago, Chile, donde se reportó que del total de pacientes atendidos en el Instituto Teletón de Santiago, un 55,4 \% de los casos corresponden a parálisis cerebral y encefalopatías y un 75,7 \% a lesiones del sistema nervioso periférico y alteraciones raquimedulares congénitas, lo cual indica que prevalece la discapacidad como consecuencia de otras disfunciones presentes en la persona (15).

\section{SALUD}
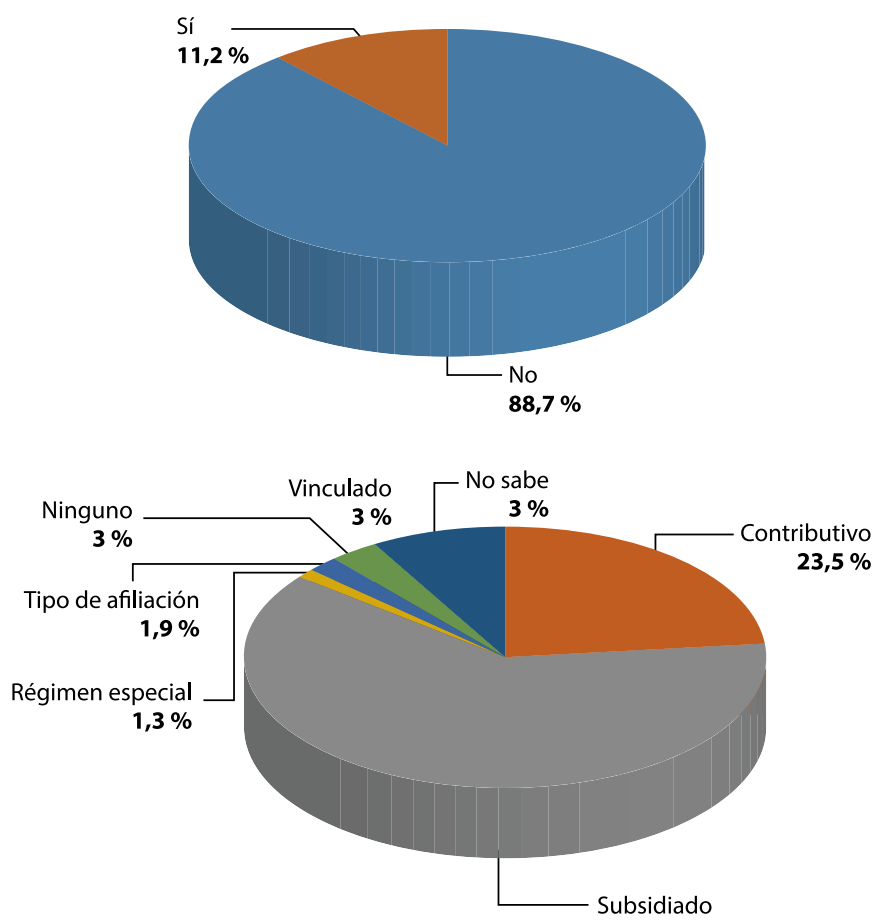

Figura 4

$62,1 \%$

Distribución de la población registrada según su afiliación y tipo de afiliación a salud 
El 88,7\% de las personas con discapacidad se encuentra afiliada al régimen de salud, mientras que un $11,2 \%$ responde que no está afiliado. De acuerdo al tipo de afiliación, un 62,1\% está afiliado al régimen subsidiado; $23,5 \%$ hace parte del régimen contributivo; $1,3 \%$ a uno de los regímenes especiales y un $8,2 \%$ no conoce el tipo de afiliación (Figura 4).

Aunque se observa en este estudio un porcentaje alto de afiliación en las personas con discapacidad, es menor a la cobertura reportada por el Ministerio de Salud en la población general, que en el año 2014 fue de 91,55 \%; en cuanto al régimen, la mayoría de los individuos están afiliados al subsidiado y aunque es el comportamiento nacional (47,7\%) al comparar las frecuencias, se observa que un menor número de personas con discapacidad pertenece al régimen contributivo (16). Según la Organización Mundial de la Salud mil millones de personas con discapacidad carecen de acceso a una atención médica y a servicios de rehabilitación especialmente en los países de ingresos bajos y medianos (17). Lo anterior incrementa la situación de vulnerabilidad y su plena inclusión y participación en todos los aspectos de la vida.

El 70,6 \% (2856 sujetos) de las personas con discapacidad considera que fue oportunamente diagnosticada, mientras que un $29,4 \%$ informa que el diagnóstico no fue oportuno. Al indagar sobre si la persona o la familia fueron orientadas sobre el manejo de la discapacidad, un 50,4 \% (2038 personas) respondió que recibió orientación y el 49,6 \% refiere no haber recibido orientación sobre cómo manejar su discapacidad.

$\mathrm{Al}$ indagar sobre si ha recibido atención en salud en el último año, el 66,5 \% (2689 personas) responde de manera positiva, mientras que el 33,5\% informa no haber recibido atención en salud por su discapacidad (Figura 5). 


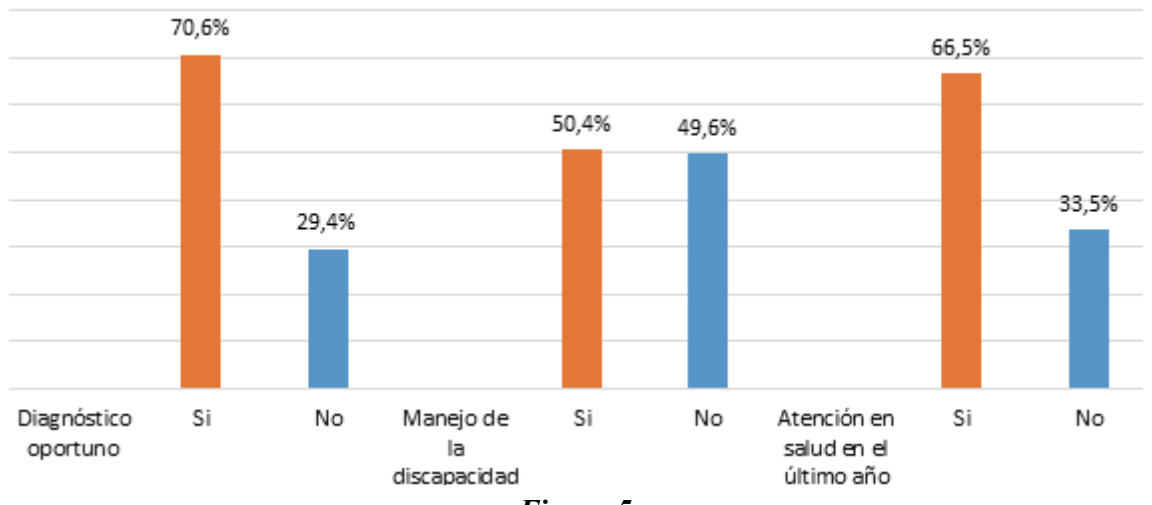

Figura 5

Distribución de la población registrada según dificultades en la prestación del servicio de salud

En el estudio de Revilla et al. (18) no se alcanzó el estándar establecido para el tiempo desde la llegada hasta la atención de la persona en el servicio de medicina física y rehabilitación; los autores explican que posiblemente por el incremento del número de individuos que requieren este tipo servicios, la atención oportuna se ve afectada. El incremento de las personas con discapacidad se explica, entre otros factores, por el acelerado envejecimiento de la población colombiana que lleva a una mayor prevalencia de enfermedades crónicas no transmisibles, las cuales aumentan las deficiencias y limitaciones funcionales de los individuos.

Como lo muestra la Tabla 11, al 58,9 \% le ordenaron ayudas especiales, prótesis o medicamentos permanentes por su discapacidad; mientras que el $41,1 \%$ responde que no le han ordenado ayudas especiales. En relación al uso de ayudas especiales, prótesis o medicamentos permanentes por su discapacidad, el 48,5 \% manifiesta que sí las utiliza actualmente; y un $51,4 \%$ informó que actualmente no utiliza ayudas especiales. El 78,1 \% de las personas con discapacidad considera que aún necesita de ayudas especiales, prótesis o medicamentos permanentes; el 21,9\% cree que no necesita estas ayudas. 


\section{Tabla 11}

Distribución de la población registrada según si le ordenó usar ayudas especiales, prótesis o medicamentos permanentes

\begin{tabular}{|l|c|c}
\hline \multicolumn{1}{l|}{ Descripción } & Frecuencia & Porcentaje \\
\hline Orden de ayudas especiales & 2383 & \\
\cline { 2 - 3 } Sí & 1661 & 58,9 \\
\hline No & & 41,1 \\
\hline Utiliza ayudas especiales actualmente & 1962 & 48,5 \\
\hline Sí & 2082 & 51,4 \\
\hline No & & \\
\hline Cree que aún necesita ayudas especiales & 3158 & 78,1 \\
\hline Sí & 886 & 21,9 \\
\hline No & & \\
\hline Requiere ayuda de otra persona & 2385 & 59,0 \\
\hline Si & 1659 & 41 \\
\hline No & & \\
\hline Persona que más le ayuda & 2029 & 85,1 \\
\hline Algún miembro del hogar & 80 & 3,4 \\
\hline Persona externa no empleada & 15 & 0,6 \\
\hline Persona externa empleada para ayudarlo & 261 & 10,9 \\
\hline Otra & 2385 & 100 \\
\hline Total & & \\
\hline
\end{tabular}

Se observa que el $59 \%$ de las personas con discapacidad registrada sí requiere ayuda permanente de otra persona; el $41 \%$ informa no necesitarla. Al indagar sobre la persona que más le ayuda para desarrollar las actividades diarias, el 85,1 \% responde que algún miembro del hogar; el 10,9\% no específica el tipo de personas que lo ayuda permanentemente.

En muchas ocasiones las personas con limitaciones en sus capacidades funcionales requieren de apoyos técnicos para mantener o incrementar su independencia y autonomía, aunque en muchos casos el acceso a ellas se dificulta, tanto es así que la OMS manifiesta que entre el 5 al $15 \%$ de las personas con discapacidad lo requiere y no tiene acceso a ellas (19), lo cual podría limitar el desempeño durante las actividades de la vida diaria 
y la satisfacción con el funcionamiento de la actividad, e igualmente, el aumento de las carga de los cuidadores (20); estos autores explican que una ayuda técnica es un elemento que se utiliza para aumentar, mantener o mejorar las capacidades funcionales de individuos con discapacidad (20).

Tabla 12

Distribución de la población registrada según se está recuperando de la discapacidad

\begin{tabular}{|l|c|c}
\hline \multicolumn{1}{|c|}{ Descripción } & Frecuencia & Porcentaje \\
\hline Recuperando de la discapacidad & & \\
\cline { 2 - 3 } Sí & 1194 & 29,5 \\
No & 2850 & 70,5 \\
\hline Total & 4044 & 100 \\
\hline A quién le atribuye su recuperación & & \\
\hline A los servicios de salud y rehabilita- & 482 & 40,4 \\
ción recibidos & & \\
Al apoyo de la familia & 349 & 29,2 \\
\hline A su empeño por salir adelante & 71 & 6 \\
\hline A la ayuda de Dios & 197 & 16,5 \\
\hline A la acción de la medicina alternativa & 14 & 1,1 \\
\hline Otro & 81 & 6,8 \\
\hline Total & 1194 & 100 \\
\hline
\end{tabular}

De la población con discapacidad registrada, el 29,5\% considera que sí se está recuperando de su discapacidad y el 70,5\% percibe que no se ha recuperado. Un mayor porcentaje $(40,4 \%)$ de personas con discapacidad refiere que su recuperación la ha logrado por los servicios de salud y rehabilitación; el 29,2 \% lo atribuye al apoyo de la familia; el 16,5 \% de estas personas considera que la ayuda de Dios ha contribuido a su recuperación; mientras que el $6 \%$ considera que su empeño por salir adelante es el factor que ha permitido su recuperación.

Las personas con discapacidad tienen mayores probabilidades de manifestar un problema de salud grave al compararlas con personas sin discapacidad, de allí que la necesidad de los servicios de rehabilitación sea 
un imperativo para esta población, aunque su uso es bajo, de acuerdo a lo reportado en el estudio de Mactaggart (21), recomendando que es necesario incrementar los conocimientos de las personas con discapacidad sobre los servicios de rehabilitación a los que pueden acceder para de esta forma asegurar el cumplimiento de sus metas como sujetos de derechos.

Tabla 13

Distribución de la población registrada según tipo de rehabilitación ordenada

\begin{tabular}{l|c|c}
\hline \multirow{2}{*}{\multicolumn{1}{c|}{ Tipo de rehabilitación }} & \multicolumn{2}{c}{ Tipo de servicios } \\
\cline { 2 - 3 } & Frecuencia & Porcentaje \\
\hline Medicina física y de rehabilitación & 873 & 21,6 \\
\hline Psiquiatría & 491 & 12,1 \\
Fisioterapia & 1175 & 29,1 \\
\hline Fonoaudiología & 585 & 14,5 \\
Terapia ocupacional & 441 & 10,9 \\
Optometría & 316 & 7,8 \\
Psicología & 590 & 14,6 \\
Trabajo Social & 223 & 5,5 \\
Medicamentos permanentes & 963 & 23,8 \\
\hline
\end{tabular}

El Registro para la Localización y Caracterización de Personas con Discapacidad permitió conocer los tipos de rehabilitación ordenadas; al respecto, la mayoría de los sujetos respondió que el servicio de fisioterapia fue el más ordenado (29,1\%), seguido de medicina física y rehabilitación (21,6 \%), el $14,6 \%$ seleccionó psicología, fonoaudiología fue escogida por el $14,5 \%$ de las personas con discapacidad, un 23,8\% necesita medicamentos de forma permanente.

En el presente estudio se observa que la rehabilitación funcional, realizada por los fisioterapeutas, es el servicio que en mayor medida reciben las personas encuestadas, lo que se podría explicar por los altos reportes de deficiencias físicas en las personas con discapacidad como lo expresa Gudlavalleti (22); en su estudio el 88, 4 \% (742) presentó alteraciones 
físicas. Los servicios de fisioterapia son esenciales en los procesos de rehabilitación de las personas con limitaciones funcionales producidas por alteraciones en la movilidad. Al respecto, los autores han reportado duración más corta de limitaciones en las personas en comparación con las que no recibieron atención por parte de un fisioterapeuta (23).

Tabla 14

Distribución de la población registrada según el servicio de rehabilitación actual

\begin{tabular}{|l|c|c}
\hline \multicolumn{1}{c|}{ Descripción servicio de rehabilitación } & Frecuencia & Porcentaje \\
\hline Asistencia actual a un servicio de rehabilitación & & \\
\hline Sí & 683 & 16,9 \\
No & 3361 & 83,1 \\
Total & 4044 & 100 \\
Pago de la rehabilitación & & \\
Sistema General de Salud & 491 & 71,9 \\
La familia & 88 & 12,9 \\
Personalmente & 17 & 2,5 \\
\hline Una ONG & 20 & 2,9 \\
El empleador & 20 & 2,9 \\
Otro & 47 & 6,6 \\
Total & 683 & 100 \\
Tipo de establecimiento & & \\
\hline Público & 310 & 45,4 \\
\hline Privado & 310 & 45,4 \\
\hline No sabe & 63 & 9,3 \\
\hline Total & 683 & 100 \\
\hline
\end{tabular}

Al indagar sobre si asiste a un servicio de rehabilitación, el 83,1\% manifiesta no asistir actualmente a un servicio de rehabilitación y solo el 16,9 \% lo hace. Respecto de quién paga los servicios de rehabilitación recibidos, de las 683 personas que sí asisten a un servicio, el 71,9\% manifiesta que el Sistema General de Salud; 12,9 \% la familia; un 2,5 \% expresa que personalmente asume los gastos de rehabilitación; y tanto una ONG como el empleador son seleccionadas por el $2,9 \%$ de las personas, respectivamente. 
Tanto los establecimientos públicos $(45,4 \%)$ como privados $(45,4 \%)$ fueron seleccionados por igual número de personas con discapacidad como el tipo de instituciones de salud donde se llevan a cabo los procesos de rehabilitación; mientras que el 9,3\% no reconoce el tipo de establecimiento donde asiste para su rehabilitación.

Los resultados muestran que el sistema de salud colombiano asume los procesos de rehabilitación en la mayoría de los participantes, hecho que coincide con lo reportado por Hernández (24), donde el 71,9 \% de las personas registradas por su estudio están aseguradas en el Sistema General de Seguridad Social en Salud; también se muestra en el estudio de Hernández (24) que el 90,6 \% no recibe servicios de rehabilitación, siendo la falta de dinero la causa principal para no asistir, hallazgos parecidos al presente estudio, como se muestra en la Tabla 15.

Tabla 15

Distribución de la población registrada según las razones de no recibir el servicio de rehabilitación

\begin{tabular}{l|c|c|c|c}
\hline \multirow{2}{*}{$\begin{array}{c}\text { Razones de no recibir el servicio de } \\
\text { rehabilitación }\end{array}$} & \multicolumn{2}{|c|}{ No } & \multicolumn{2}{c}{ Sí } \\
\cline { 2 - 5 } & Frecuencia & Porcentaje & Frecuencia & Porcentaje \\
\hline Ya terminó la rehabilitación & 3138 & 93,4 & 223 & 6,6 \\
Cree que ya no lo necesita & 3166 & 94,2 & 195 & 5,8 \\
No le gusta & 3230 & 96,1 & 131 & 3,9 \\
\hline Falta de dinero & 1728 & 51,4 & 1633 & 48,6 \\
\hline El centro de atención queda muy lejos & 3036 & 90,3 & 325 & 9,7 \\
\hline No hay quien lo lleve & 3160 & 94,0 & 201 & 5,9 \\
\hline
\end{tabular}

La principal razón por la cual las personas con discapacidad encuestadas no reciben el servicio de rehabilitación es no le gusta $(96,1 \%)$, el creer que ya no necesitan estos servicios fue seleccionada por el 94,2\% de los sujetos, otra de las razones que obtuvo un alto porcentaje ( $94 \%$ ) fue no tener una persona que lo lleve al establecimiento donde se realizan los procesos de rehabilitación, en menor proporción $(51,4 \%)$ fue seleccionada la falta de dinero como un factor para no recibir el servicio de rehabilitación. 
Tabla 16

Promedio de años sin recibir los servicios de rehabilitación

\begin{tabular}{c|c}
\hline Media & Desviación estándar \\
\hline 12,2 años & 14,7 años \\
\hline
\end{tabular}

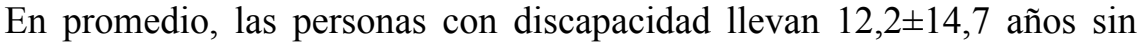
recibir los servicios de rehabilitación.

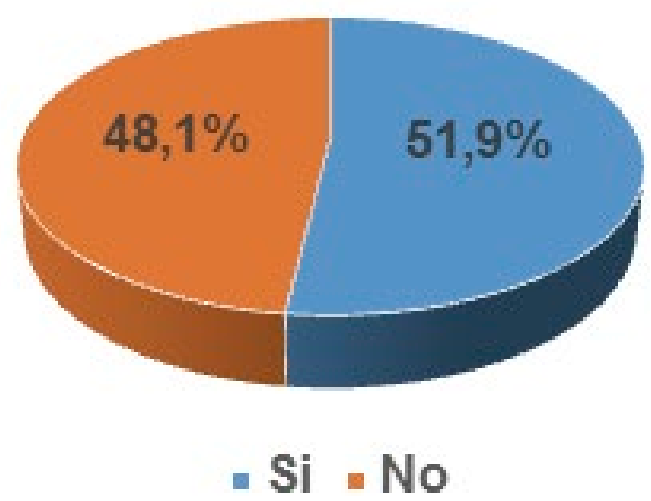

Figura 6

Distribución de la población registrada según si sabe si el municipio cuenta con servicio de rehabilitación

De la población registrada el 51,9 \% (2100 sujetos) sí sabe que el municipio cuenta con servicio de rehabilitación y un $48,1 \%$ no sabe si el municipio cuenta con este servicio.

Inquieta que un porcentaje alto de personas con discapacidad desconozca la existencia de servicios de rehabilitación en sus entornos cercanos; en relación con lo anterior, organismos internacionales expresan que los sistemas de salud deben ser reorientados y fortalecidos para asegurar el acceso equitativo y de calidad a las personas con discapacidad, debido a que cada día suelen tener más necesidades de salud, y menos posibilidades de encontrar los servicios que necesitan (25). 
La calidad en la prestación de los servicios de salud se fundamenta en un conjunto de principios organizativos y en Colombia está respaldada por un marco legal amplio donde se resaltan características del sistema de salud, la accesibilidad, oportunidad, seguridad, pertinencia y continuidad; convirtiéndose estas características en las influencias contextuales que actúan como facilitadores para el individuo con discapacidad (26).

Aunque en Barranquilla existe una cobertura total, ideal necesario para la equidad social, en las actuales condiciones de deterioro económico y social del país, el cumplimiento de dichas características no se realiza de una manera completa (27) Rubio (28) comenta que la población de mayores necesidades en salud y menores ingresos no acceden a los servicios de salud aun estando afiliados al sistema; la población con discapacidad presenta estas peculiaridades, mostrando pocas oportunidades para acceder a servicios de salud de calidad, disminuyendo las posibilidades de ingresar a procesos de rehabilitación de calidad que incremente sus capacidades de generar ingresos, situación que aumenta la vulnerabilidad de esta población (29).

\section{EDUCACIÓN}

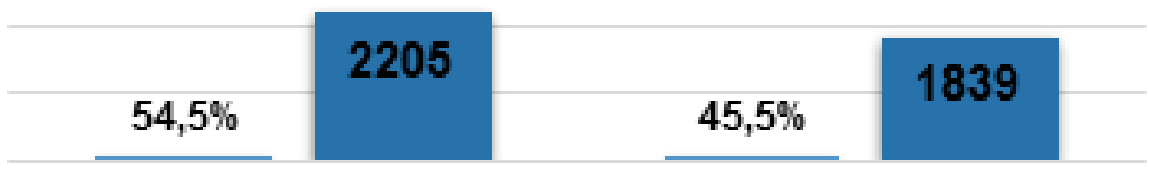

Si

No

Figura 7

Distribución de la población registrada según si sabe leer o escribir 
El 54,5\% de las personas registradas sabe leer o escribir, mientras que un $45,5 \%$ responde que no sabe leer o escribir.

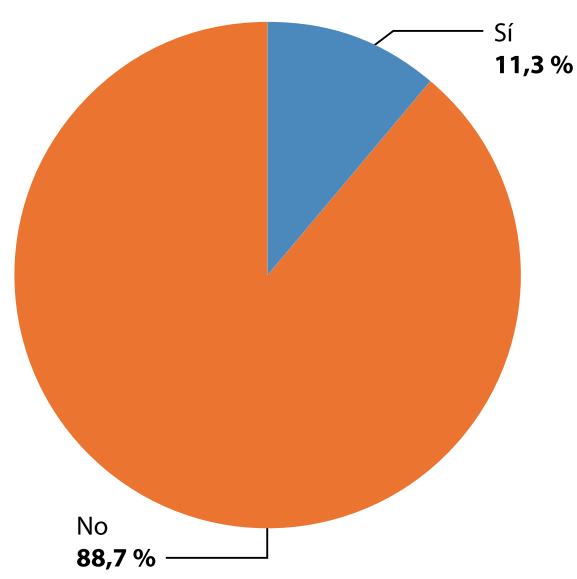

Figura 8

Distribución de la población registrada según si asiste actualmente a un establecimiento educativo

El 88,7 \% (3588 sujetos) de la población registrada informa que no asiste actualmente a un establecimiento educativo, solo el 11,3\% asiste actualmente a una institución educativa.

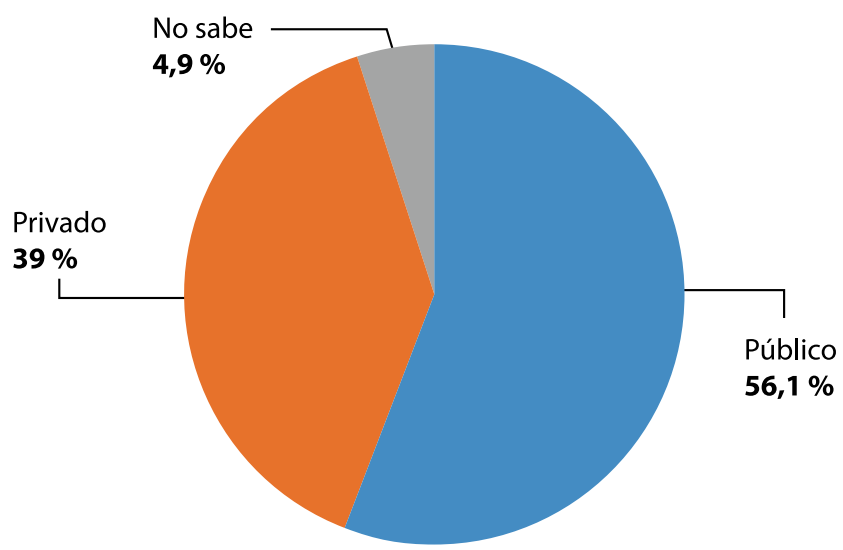

Figura 9

Distribución de la población registrada según tipo de establecimiento educativo 
Con relación al tipo de establecimiento educativo, el 56,1 \% (256 personas) de los que asisten a ellos la reconocen como establecimientos públicos; un $39 \%$ estudia en instituciones educativas privadas; y solo $4,9 \%$ no reconoce el tipo de institución.

\section{Tabla 17}

Distribución de la población registrada según los servicios de apoyo con los que cuenta el establecimiento educativo donde estudian las personas con discapacidad.

\begin{tabular}{l|c|c|c|c}
\hline \multirow{2}{*}{$\begin{array}{c}\text { Servicios de apoyo de las } \\
\text { instituciones educativas }\end{array}$} & \multicolumn{2}{c|}{ Sí } & \multicolumn{2}{c}{ No } \\
\cline { 2 - 5 } & Frecuencia & Porcentaje & Frecuencia & Porcentaje \\
\hline Pedagógicos & 225 & 49,3 & 231 & 50,7 \\
Tecnológicos & 89 & 19,5 & 367 & 80,5 \\
Terapéuticos & 115 & 25,2 & 341 & 74,8 \\
\hline
\end{tabular}

La Tabla 17 muestra una mayor proporción de respuestas negativas sobre los servicios de apoyo en las instituciones educativas donde asisten las personas con discapacidad. El 50,7 \% de las personas manifiesta que las instituciones educativas no cuentan con servicios pedagógicos que apoyen los procesos educativos de las personas con discapacidad; el 80,5\% expresa que no cuentan con servicios tecnológicos que ayuden con las actividades de los estudiantes. Igualmente relevante que el 74,8 \% de las personas reconozca que las instituciones educativas donde asisten no cuentan con servicios terapéuticos que apoyen sus actividades.

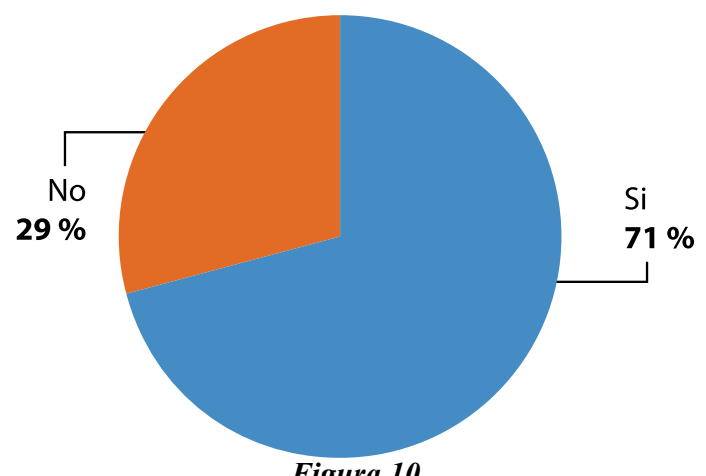

Distribución de la población registrada según los docentes atienden adecuadamente sus necesidades educativas especiales 
En relación a si los docentes atienden adecuadamente sus necesidades educativas especiales, la Figura 10 muestra que el $71 \%$ (324 personas) responde que sí lo hacen; el $29 \%$ señala que los docentes no atienden de manera adecuada sus necesidades educativas.

Tabla 18

Distribución de la población registrada según la causa principal por la cual no estudia

\begin{tabular}{l|c|c}
\hline \multicolumn{1}{c|}{ Causas por las que no estudia } & Frecuencia & Porcentaje \\
\hline Porque ya terminó o considera que no está en edad escolar & 763 & 21,3 \\
Costos educativos elevados o falta de dinero & 425 & 11,8 \\
Por falta de tiempo & 71 & 2 \\
No aprobó el examen de ingreso & 6 & 0,2 \\
Falta de cupos & 17 & 0,5 \\
No existe centro educativo cercano & 70 & 1,9 \\
Necesita trabajar & 99 & 2,8 \\
No le gusta o no le interesa el estudio & 84 & 2,3 \\
Perdió el año o fue expulsado & 10 & 0,3 \\
Su familia no quiere que estudie & 24 & 0,7 \\
Por su discapacidad & 1216 & 33,9 \\
Otra causa & 803 & 22,4 \\
Total & 3588 & 100 \\
\hline
\end{tabular}

En relación a la causa principal por la que no estudia, el 33,9\% responde que por su discapacidad, el 21,3\% porque ya terminó o considera que no está en edad escolar y el 11,8\% porque los costos educativos son elevados, o por falta de dinero.

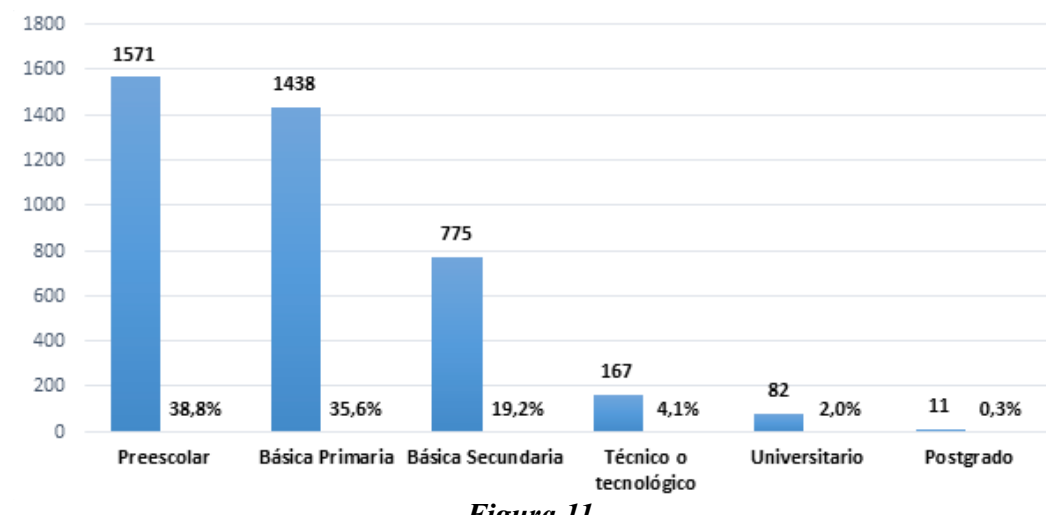

Figura 11

Distribución de la población registrada según el último año escolar que aprobó 
Se observan bajos porcentajes de personas que registran la culminación de estudios de nivel técnico, tecnológicos o universitarios. El mayor porcentaje solo culminó el preescolar (38,8 \%), mientras que un 35,6 \% alcanzó la básica primaria. Los niveles de escolaridad universitaria y posgrado presentan muy bajos porcentajes de acceso.

Tabla 19

Distribución de la población registrada según si la educación que ha recibido responde a sus necesidades y según si le dieran la oportunidad de estudiar o seguir estudiando lo haría

\begin{tabular}{l|c|c}
\hline Responde a sus necesidades & Frecuencia & Porcentaje \\
\cline { 2 - 3 } Sí & 1373 & 34 \\
No & 2671 & 56 \\
Oportunidad de seguir estudiando & & \\
Sí & 2810 & 69,5 \\
No & 1234 & 30,5 \\
Total & 4044 & 100 \\
\hline
\end{tabular}

El $34 \%$ de las personas responde que la educación recibida responde a sus necesidades; el $56 \%$ manifiesta que no responde a sus necesidades. También se observa en la Tabla 19 que el 69,5\% de la población registrada afirma que ante la oportunidad de estudiar o continuar estudiando la aceptaría; mientras que el 30,5\% responde que no lo haría.

En general se observa en los resultados concernientes a los procesos educativos que la inclusión al sector educativo no es la adecuada en esta población participante. Al respecto, Hernández (24) expresa que el $90 \%$ de su población estudiada no tiene educación básica secundaria; por otro lado, otros autores (30) reportan que en Colombia las metas de aprendizaje en la población de estudio es mínima, posiblemente por una baja formación de los docentes que limitan la respuesta oportuna y adecuada a las necesidades de las personas con discapacidad.

Los resultados del presente estudio muestran altos porcentajes de perso- 
nas analfabetas, aunque no tan alta frecuencia. Padilla (31) reporta que el $22,5 \%$ de las personas en condición de discapacidad son analfabetas; igualmente, se muestra que el $80 \%$ de los profesores no se sienten preparados para atender las necesidades de estudiantes con discapacidad sensorial o mental. De lo anterior se puede inferir que la inclusión escolar está influenciada, entre otros, por la baja capacitación de los profesores, lo cual disminuye las oportunidades educativas que son las que posibilitarán la inclusión de las personas con discapacidad al mercado laboral y a mayores garantías del disfrute de los bienes y servicios que tienen como sujetos de derecho.

\section{PARTICIPACIÓN EN ACTIVIDADES FAMILIARES O COMUNITARIAS}

Tabla 20

Distribución de la población registrada según las actividades en que participa

\begin{tabular}{l|c|c|c|c}
\hline \multirow{2}{*}{ Participación en actividades } & \multicolumn{2}{|c|}{ Sí } & \multicolumn{2}{c}{ NO } \\
\cline { 2 - 5 } & Frecuencia & Porcentaje & Frecuencia & Porcentaje \\
\hline Con la familia y amigos & 2045 & 50,6 & 1999 & 49,4 \\
Con la comunidad & 718 & 17,8 & 3326 & 82,2 \\
Religiosas o espirituales & 991 & 24,5 & 3053 & 75,5 \\
Productivas & 102 & 2,5 & 3942 & 97,5 \\
Deportivas o de recreación & 316 & 7,8 & 3728 & 92,2 \\
Culturales & 152 & 3,8 & 3892 & 96,2 \\
Educación no formal & 39 & 1,0 & 4005 & 99 \\
Ciudadanas & 55 & 1,4 & 3989 & 98,6 \\
Otras & 68 & 1,7 & 3976 & 98,3 \\
\hline
\end{tabular}

Las actividades donde se observó una mayor participación de las personas con discapacidad son con la familia y amigos (50,6\%), seguida de actividades religiosas o espirituales (24,5\%). El $99 \%$ dice no participar en educación no formal; es baja la participación de las personas con discapacidad en actividades ciudadanas $(98,6 \%)$, productivas $(97,5 \%)$ y culturales $(96,2 \%)$. 


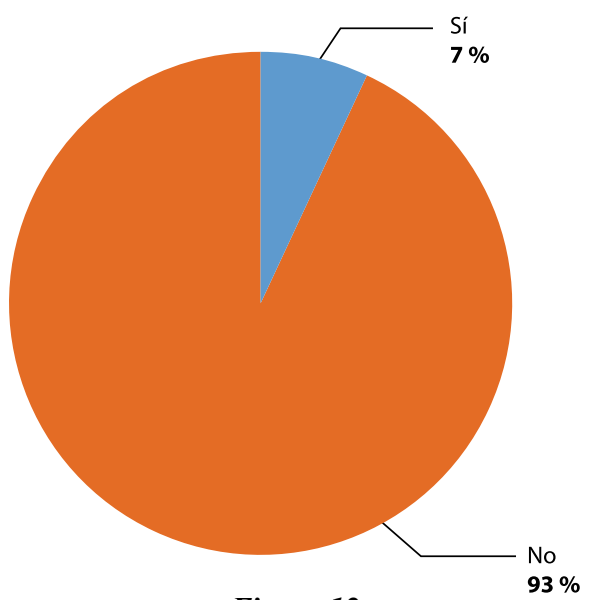

Figura 12

Distribución de la población registrada según si actualmente participa en alguna organización

E1 $93 \%$ de la población registrada con discapacidad no participa en ninguna organización y solo el 7 \% sí lo hace.

Tabla 21

Distribución de la población registrada según la razón principal por la cual no participa en una organización

\begin{tabular}{l|c|c}
\hline \multicolumn{1}{c|}{ Razón por la que no participa en una organización } & Frecuencia & Porcentaje \\
\hline Falta de dinero & 450 & 12 \\
Falta de tiempo & 172 & 4,6 \\
No existe o no la conoce & 558 & 14,9 \\
Siente rechazo & 63 & 1,7 \\
Por su discapacidad & 1.384 & 37 \\
No cree en ellas & 65 & 1,7 \\
Sus principios o creencias se lo impiden & 3 & 0,1 \\
Prefiere resolver sus problemas solo & 75 & 2 \\
Otra & 973 & 26 \\
Total & 3.743 & 100 \\
\hline
\end{tabular}

El $37 \%$ de la población registrada con discapacidad no participa en ninguna organización por la discapacidad que presenta; $14,9 \%$ porque no la conoce o dice que no existe; el $12 \%$ por falta de dinero; $26 \%$ expresa que son otras razones las que no le permiten participar en estas organizaciones; 4,6\% 
dice que por falta de tiempo; el $2 \%$ dice que prefiere resolver sus problemas solo; un $1,7 \%$ dice que siente rechazo y otro $1,7 \%$ dice no creer en esas organizaciones, por lo menos el $0,1 \%$ menciona que no participan por sus principios o creencias religiosas.

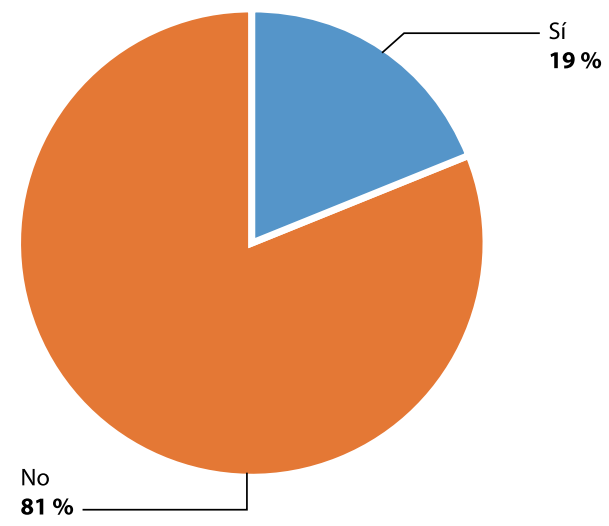

Figura 13

Distribución de la población registrada según su participación en una organización en defensa de los derechos de la población con discapacidad

El $81 \%$ de las personas registradas con discapacidad actualmente no participa en organizaciones en defensa de los derechos de la población con discapacidad; solamente el $19 \%$ dice que sí participaría.

Con relación a la participación social de las personas con discapacidad, llama la atención que las personas se sienten mas cómodas en su entorno familiar, donde no perciben que las barreras arquitectónicas le limiten la integración social como se observa en un estudio que incluyó el total de personas identificadas en el Registro del DANE para la Localización y Caracterización de Persona con Discapacidad en Santiago de Cali; así, los resultados se correlacionan dado que se identificó que el $51 \%$ de la población participa en actividades sociales especialmente en las familiares y con amigos, el 38,3\% en actividades religiosas, otro $24,4 \%$ en actividades organizadas por la comunidad y un $11,2 \%$ en actividades deportivas o re- 
creativas; solamente se reportó que el $25 \%$ tiene algún tipo de restricción para participar (10).

Con relación a las actividades comunitarias, el $67 \%$ de 45 sujetos encuestados en Cali manifestó que en alguna forma tiene dificultad para disfrutar del derecho al entorno físico, la información y la comunicación, un $73 \%$ dice por la falta de accesibilidad, un $63 \%$ por restricción para sentirse en igualdad de oportunidades y otro 59 \% por percibir discriminación de las personas sin limitaciones (8).

\section{TRABAJO EN MAYORES DE 10 AÑOS}

Tabla 22

Distribución de la población mayor de 10 años registrada según en los últimos 6 meses que ha estado realizando principalmente

\begin{tabular}{l|c|c}
\hline \multicolumn{1}{c|}{ Qué ha estado haciendo } & Frecuencia & Porcentaje \\
\hline Trabajando & 254 & 6,8 \\
Buscando trabajo & 169 & 4,6 \\
Incapacitado permanente para trabajar-sin pensión & 1151 & 31 \\
Incapacitado permanente para trabajar-con pensión & 124 & 3,3 \\
Estudiando & 185 & 5 \\
Realizando oficios del hogar & 417 & 11,2 \\
Recibiendo renta & 6 & 0,2 \\
Pensionado-jubilado & 49 & 1,3 \\
Realizando actividades de autoconsumo & 49 & 1,3 \\
Otra actividad & 1309 & 35,2 \\
Total & 3713 & 100 \\
\hline
\end{tabular}

De la población encuestada y registrada con discapacidad el $31 \%$ dice haber estado incapacitado permanente para trabajar y sin pensión durante los últimos seis meses; $6,8 \%$ ha estado trabajando en este lapso de tiempo; $5 \%$ ha estado estudiando; $4,6 \%$ ha estado buscando trabajo; 3,3\% ha estado incapacitado permanente para trabajar - con pensión; 35,2\% dice haber estado dedicado a otras actividades diferentes los últimos seis meses. 
Solamente el 1,3\% ha estado pensionado - jubilado, y el mismo porcentaje ha estado realizando actividades de autoconsumo.

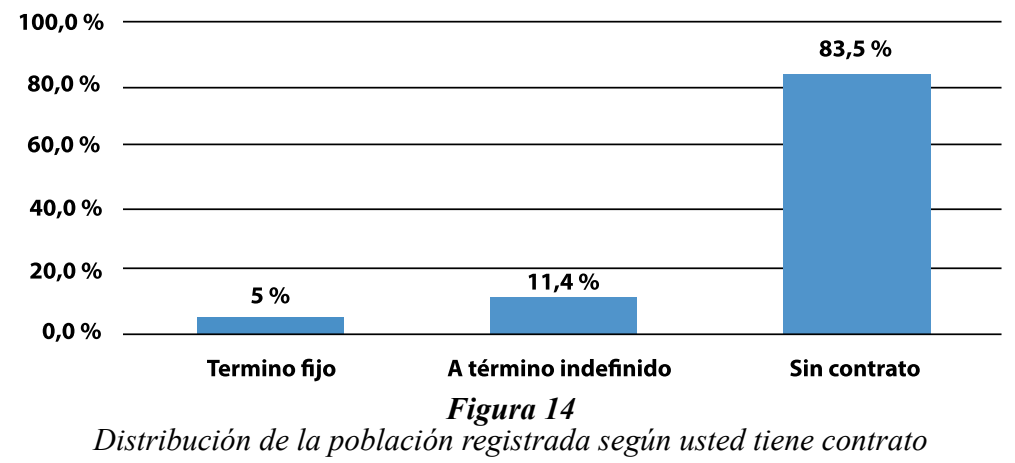

El 83,5 \% de las personas con discapacidad que reportaron estar trabajando actualmente, expresa no tener contrato de trabajo; $11,4 \%$ tiene contrato a término indefinido; $5,1 \%$ tiene contrato a término fijo.

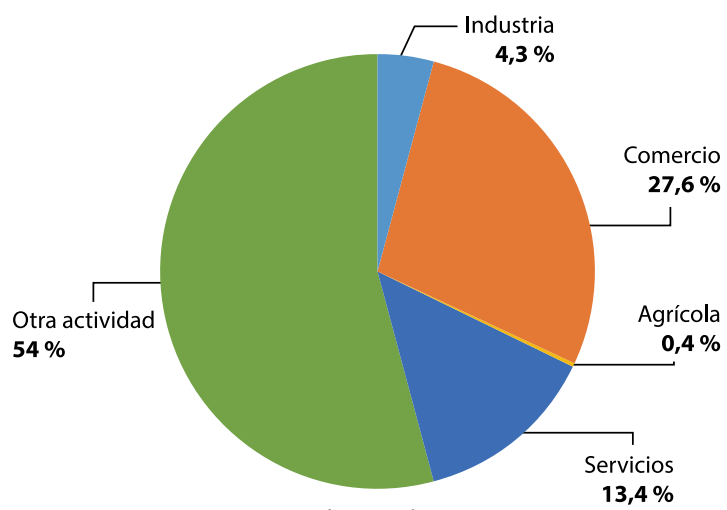

Figura 15

Distribución de la población registrada según la actividad económica que realiza en su trabajo

El 27,6 \% de las personas con discapacidad se dedica al comercio; $13,4 \%$ ofrece servicios; $4,3 \%$ se dedica a la industria mientras que $54 \%$ se dedica 
a otras actividades económicas. Solo un $0,4 \%$ se dedica a actividades agrícolas y otro porcentaje similar a las actividades pecuarias.

Tabla 23

Distribución de la población registrada según el desempeño en su trabajo

\begin{tabular}{l|c|c|}
\hline \multicolumn{1}{c|}{ Desempeño laboral } & Frecuencia & Porcentaje \\
\hline Obrero-empleado del gobierno & 10 & 3,9 \\
\hline Obrero-empleado particular & 50 & 19,7 \\
Jornalero o peón & 1 & 0,4 \\
Patrón o empleador & 6 & 2,4 \\
Trabajador por cuenta propia & 132 & 52 \\
Empleado(a) doméstico(a) & 21 & 8,2 \\
Trabajador familiar sin remuneración & 10 & 3,9 \\
No especifica & 24 & 9,4 \\
\hline Total & 254 & 100 \\
\hline
\end{tabular}

El $52 \%$ se desempeña como trabajador independiente; $19,7 \%$ es obrero-empleado particular; 9,4\% tiene un desempeño no específico; $8,2 \%$ es empleado(a) doméstico(a); 3,9\% se desempeña como trabajador familiar sin remuneración; $2,4 \%$ se desempeña como patrón o empleador; $0,4 \%$ se desempeña como jornalero o peón.

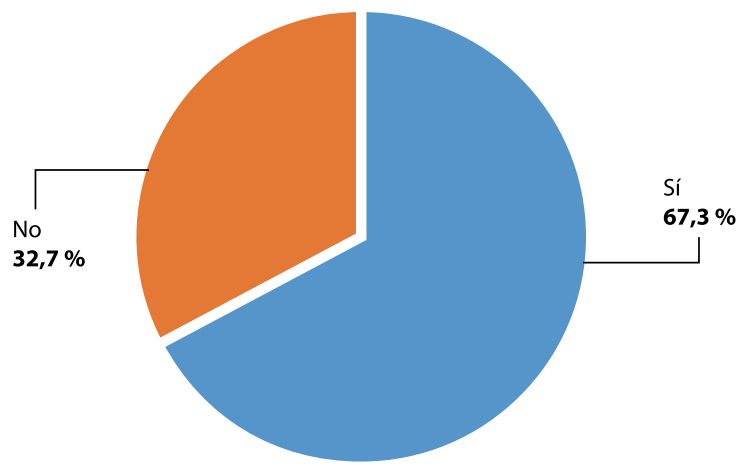

Figura 16

Distribución de la población registrada según su capacidad para el trabajo que se ha visto afectada como consecuencia de su discapacidad 
El $67,3 \%$ dice que su capacidad para el trabajo sí se ha visto afectada como consecuencia de la discapacidad que presenta, mientras que el $32,7 \%$ afirma que no se ha visto afectada.

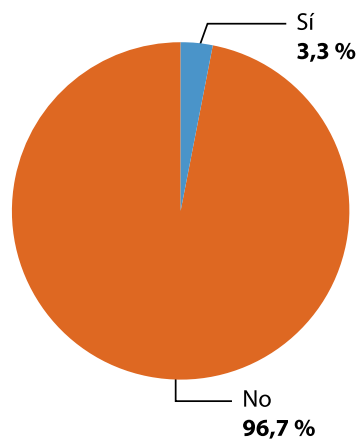

Figura 17

Distribución de la población registrada que luego de presentar su discapacidad, ha recibido capacitación para el trabajo

El 96,7 \% de las personas registradas con discapacidad dice no haber recibido capacitación para el trabajo luego de presentar la discapacidad. Entre tanto que el 3,3\% dice que sí lo ha recibido.

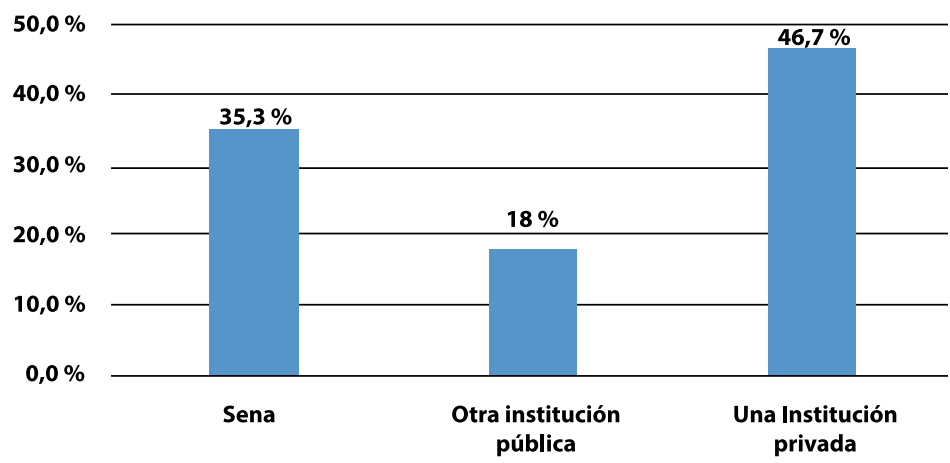

Figura 18

Barranquilla. Distribución de la población registrada según la institución donde realizó la capacitación

El 35,3 \% de las personas que ha recibido capacitación para el trabajo luego de presentar una discapacidad dice haber sido capacitado por el SENA; $46,7 \%$ por una institución privada; $18 \%$ por una institución pública. 


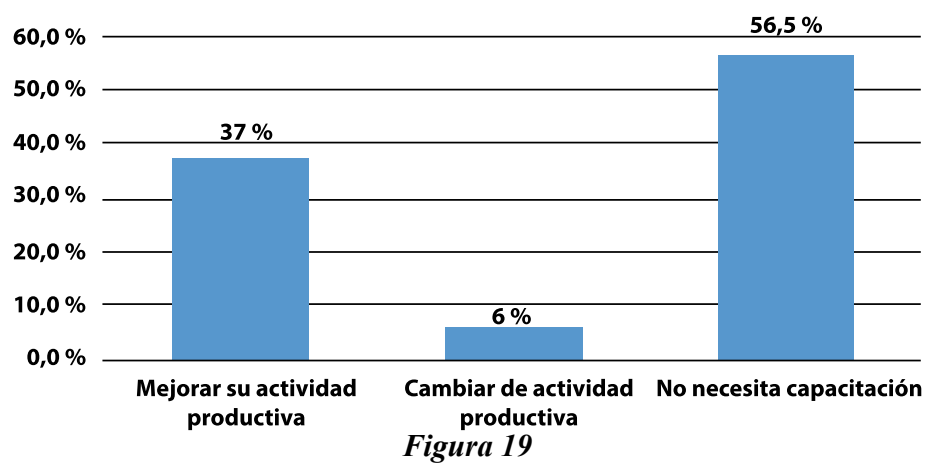

Distribución de la población registrada según necesita capacitación para mejorar su actividad productiva

El 37,4 \% de la población registrada con discapacidad dice necesitar capacitación para mejorar su actividad productiva; $56,5 \%$ dice no necesitar capacitación; el $6 \%$ dice necesitarla para cambiar de actividad productiva.

Con relación al trabajo remunerado, estudios han descrito que las personas con discapacidad se sienten con menor oportunidad de acceder a desempeñarse en oficios laborales; tal es el caso de personas en la ciudad de Cali de las cuales un porcentaje elevado del $73 \%$ de 45 personas encuestadas, indicó tener dificultades para acceder a un trabajo remunerado, quienes laboraban, lo hacían de manera independiente con ingresos económicos hasta de un salario mínimo legal vigente (8).

Así mismo, en la vereda de Los Tres del municipio de Los Santos, en Santander, se han encontrado reportes que indican que el $44 \%$ de las personas con discapacidad permanente para trabajar no recibía tampoco pensión por invalidez; el 90 \% no trabajaba, el 77 \% atribuye a la discapacidad la razón por la cual no trabajaba. Se ha observado además que a un $88,9 \%$ no le interesaba trabajar, un $66,7 \%$ indicó que la discapacidad le había limitado el poder trabajar y un 45,4 \% no había trabajado en el último año (32). 


\section{ANÁLISIS BIVARIADO}

Tabla 24

Comparativo de la población registrada según el área y el sexo

\begin{tabular}{l|c|c|c|c}
\hline \multicolumn{5}{|c}{ Área } \\
\hline \multicolumn{1}{c|}{ Sexo } & Cabecera & Centro poblado & Rural disperso & Total \\
\hline Hombre & 1708 & 493 & 60 & 2261 \\
& $75,5 \%$ & $21,8 \%$ & $2,7 \%$ & $100 \%$ \\
Mujer & 1332 & 417 & 34 & 1783 \\
& $74,7 \%$ & $23,4 \%$ & $1,9 \%$ & $100 \%$ \\
Total & 3040 & 910 & 94 & 4044 \\
\hline
\end{tabular}

En el estudio se encontró que de la población registrada 75,5 \% de los hombres residen en la cabecera de la ciudad, mientras que el $74,7 \%$ es mujer.

Tabla 25

Comparativo de la población registrada según el estrato y el sexo

\begin{tabular}{l|c|c|c|c|c|c|c|c}
\hline \multicolumn{1}{c}{ Estrato socioeconómico } \\
\hline \multicolumn{1}{c|}{ Sexo } & $\mathbf{1}$ & $\mathbf{2}$ & $\mathbf{3}$ & $\mathbf{4}$ & $\mathbf{5}$ & $\mathbf{6}$ & $\mathbf{7}$ & Total \\
\hline Hombre & 1392 & 486 & 355 & 23 & 3 & 0 & 2 & 2261 \\
& $61,6 \%$ & $21,5 \%$ & $15,7 \%$ & $1,0 \%$ & $0,1 \%$ & $0 \%$ & $0,1 \%$ & 100 \\
\multirow{2}{*}{ Mujer } & 1111 & 342 & 316 & 9 & 2 & 1 & 2 & 1783 \\
& $62,3 \%$ & $19,2 \%$ & $17,7 \%$ & $0,5 \%$ & $0,1 \%$ & $0,1 \%$ & $0,1 \%$ & 100 \\
Total & 2503 & 828 & 671 & 32 & 5 & 1 & 4 & 4044 \\
\hline
\end{tabular}

El análisis de los sujetos participantes según el estrato socioeconómico evidenció que $61,6 \%$ fue hombres y el $62,3 \%$ fueron mujeres que pertenecen al estrato 1 . 
Tabla 26

Comparativo de la población registrada según la etnia y el sexo

\begin{tabular}{c|r|r|r|r|r|r|c|c|c}
\hline \multicolumn{1}{c}{ Sexo } & Negro & Raizal & $\begin{array}{r}\text { Palen- } \\
\text { quero }\end{array}$ & Gitano & Indígena & $\begin{array}{c}\text { Mestizo o } \\
\text { diferente }\end{array}$ & Chi2 & $\begin{array}{c}\text { P } \\
\text { valor }\end{array}$ & Phi \\
\hline Hombre & 151 & 55 & 5 & 1 & 9 & 2040 & $13,849 \mathrm{a}$ & 0,031 & 0,059 \\
& $6,7 \%$ & $2,4 \%$ & $0,2 \%$ & $0,0 \%$ & $0,4 \%$ & $90,2 \%$ & & & \\
Mujer & 115 & 22 & 5 & 0 & 7 & 1634 & & & \\
& $6,4 \%$ & $1,2 \%$ & $0,3 \%$ & $0,0 \%$ & $0,4 \%$ & $91,6 \%$ & & & \\
\hline
\end{tabular}

Con respecto a la raza tanto hombres como mujeres $(90,2 \%$ y $91,6 \%$ respectivamente), pertenecen al grupo de los mestizos; en menores porcentajes se encontró negros y raizales. Se encontró asociación estadísticamente significativa entre la etnia y el sexo masculino, donde la magnitud de la fuerza es nula.

Los resultados del presente estudio muestran cómo las inequidades sociales están presentes en todos los países, pero en algunos se presentan con mayor énfasis y afectan al género femenino, en lo cual las principales inequidades sociales en servicios de salud son el acceso a la atención y el diagnóstico oportuno (33). El sexo femenino está expuesto a factores de riesgo relacionados con el hogar, dadas las características y las condiciones de la vivienda; además, están más propensas a enfermedades de transmisión sexual, con consecuencias graves para el sexo masculino (33).

Al comparar estos estudios que muestran el predominio del género femenino sobre el masculino en la presencia de discapacidad, con el presente estudio se identifica que el $52 \%$ del género relacionado con la discapacidad mostró niveles de asociación estadísticamente significativos, situación que también es evidente para el caso del distrito de Barranquilla, y tal como lo refieren Vélez y Vidarte (34) los aspectos socio-demográficos para la población muestran diferencias por género los cuales concuerdan con los resultados del censo DANE 2005 para Barranquilla, donde se reporta 
que del total de la población con discapacidad la relación hombre: mujer resulta ser similar y según lo establecido en España, el género femenino es el que se ve más afectado en cuanto a condiciones de salud, al igual que quienes carecen de un ingreso mensual (35).

De igual manera estos datos resultan similares a los encontrados en el estudio de Chile en el año 2005, donde las mujeres con discapacidad fueron un 58,2 \% (33). De igual manera, el grupo etario de 10-34 años de edad es el de mayor porcentaje presentado en un $40 \%$, datos diferentes al estudio de Chile mencionado anteriormente, que señala un porcentaje de $35,1 \%$ en los mayores de 60 años (33).

Tabla 27

Comparativo de la población registrada según las alteraciones permanentes y el sexo

\begin{tabular}{|c|c|c|c|c|c|c|c|c|}
\hline $\begin{array}{l}\text { Alteraciones } \\
\text { permanentes }\end{array}$ & Total & Hombres & $\begin{array}{c}\% \\
\text { Hombres }\end{array}$ & Mujeres & $\begin{array}{c}\% \\
\text { Mujeres }\end{array}$ & Chi2 & $\begin{array}{c}\mathbf{P} \\
\text { valor }\end{array}$ & Phi \\
\hline Sistema Nervioso & 2404 & 1334 & 55,5 & 1070 & 44,5 & & & \\
\hline Ojos & 3081 & 1784 & 56,7 & 1333 & 43,3 & & & \\
\hline Oídos & 3446 & 1931 & 56 & 1515 & 44 & 3,57 & 0,03 & 0,030 \\
\hline Demás sentidos & 3904 & 2183 & 60 & 1721 & 40 & & & \\
\hline Voz y habla & 2636 & 1451 & 55 & 1185 & 45 & & & \\
\hline $\begin{array}{l}\text { Sistema } \\
\text { cardiorrespiratorio }\end{array}$ & 3682 & 2059 & 56 & 1623 & 44 & & & \\
\hline $\begin{array}{l}\text { Digestión, metabo- } \\
\text { lismo y hormonas }\end{array}$ & 3814 & 2122 & 55,6 & 1692 & 44,4 & & & \\
\hline $\begin{array}{l}\text { Sistema genital y } \\
\text { reproductivo }\end{array}$ & 3885 & 2157 & 55,5 & 1728 & 44,5 & 6,05 & 0,00 & 0,03 \\
\hline $\begin{array}{l}\text { Movimiento del } \\
\text { cuerpo }\end{array}$ & 1930 & 1095 & 56,7 & 835 & 43,3 & & & \\
\hline Piel & 3876 & 2169 & 56 & 1707 & 44 & & & \\
\hline
\end{tabular}

Con respecto a las alteraciones registradas por la población encuestada, se observó que las alteraciones permanentes en el sistema nervioso fueron registradas en el 55,5\% de los hombres y en el 44,5\% de las mujeres; las alteraciones de la voz y el habla se presentaron en un $55 \%$ de los hombres y en un $45 \%$ de las mujeres. Las alteraciones de los genitales representaron 
el 55,5\% de las alteraciones en las mujeres, mientras que para los hombres el 44,4 \%; las alteraciones permanentes del movimiento del cuerpo, manos, brazos y piernas están presentes en el 56,7 \% de los hombres y en el $43,3 \%$ de las mujeres.

Las alteraciones de la piel se observaron con mayor predominio en los participantes del sexo masculino, evidenciándose en un $56 \%$, y en un $44 \%$ en las mujeres. Se evidencia asociación estadísticamente significativa en las alteraciones permanentes de los oídos, el sistema genital y reproductivo y el sexo, siendo la magnitud de la fuerza de asociación nula.

Tabla 28

Comparativo de la población registrada según las dificultades permanentes y el sexo

\begin{tabular}{|c|c|c|c|c|c|c|c|c|}
\hline $\begin{array}{l}\text { Dificultades per- } \\
\text { manentes para }\end{array}$ & Total & Hombres & $\begin{array}{c}\% \\
\text { Hombres }\end{array}$ & Mujeres & $\begin{array}{c}\% \\
\text { Mujeres }\end{array}$ & Chi2 & $\begin{array}{c}P \\
\text { valor }\end{array}$ & Phi \\
\hline Pensar & 2640 & 1483 & 56,2 & 1157 & 43,8 & 8,933 & 0,003 & $-0,047$ \\
\hline $\begin{array}{l}\text { Percibir la luz, } \\
\text { distinguir objetos }\end{array}$ & 3457 & 1940 & 56,1 & 1517 & 43,9 & & & \\
\hline $\begin{array}{l}\text { Oir aun con apara- } \\
\text { tos especiales }\end{array}$ & 3709 & 2081 & 56,1 & 1628 & 43,9 & & & \\
\hline $\begin{array}{l}\text { Distinguir sabores } \\
\text { u olores }\end{array}$ & 3905 & 2175 & 55,7 & 1628 & 44,3 & & & \\
\hline $\begin{array}{l}\text { Hablar y } \\
\text { comunicarse }\end{array}$ & 2631 & 1426 & 54,2 & 1205 & 45,8 & & & \\
\hline $\begin{array}{l}\text { Desplazarse en } \\
\text { trechos cortos }\end{array}$ & 3643 & 2044 & 56,1 & 1599 & 43,9 & & & \\
\hline $\begin{array}{l}\text { Masticar, tragar, } \\
\text { asimilar }\end{array}$ & 3769 & 2120 & 56,2 & 1649 & 43,8 & & & \\
\hline $\begin{array}{l}\text { Retener o expul- } \\
\text { sar la orina }\end{array}$ & 3687 & 2044 & 55,4 & 1643 & 44,6 & 3,774 & 0,052 & $-0,031$ \\
\hline $\begin{array}{l}\text { Caminar, correr, } \\
\text { saltar }\end{array}$ & 2085 & 1219 & 58,5 & 866 & 41,5 & 11,40 & 0,001 & 0,053 \\
\hline $\begin{array}{l}\text { Mantener piel, } \\
\text { uñas y cabellos }\end{array}$ & 3837 & 2147 & 56 & 1690 & 44 & & & \\
\hline $\begin{array}{l}\text { Relacionarse } \\
\text { con las demás } \\
\text { personas }\end{array}$ & 3467 & 1920 & 55,4 & 1547 & 44,6 & & & \\
\hline $\begin{array}{l}\text { Llevar, mover, } \\
\text { utilizar objetos }\end{array}$ & 3351 & 1878 & 56 & 1473 & 44 & & & \\
\hline $\begin{array}{l}\text { Cambiar y mante- } \\
\text { ner posiciones }\end{array}$ & 3333 & 1858 & 55,7 & 1475 & 44,3 & & & \\
\hline $\begin{array}{l}\text { Alimentarse, } \\
\text { asearse y vestirse }\end{array}$ & 3266 & 1826 & 55,9 & 1440 & 44,1 & & & \\
\hline Otra & 3898 & 2177 & 55,8 & 1721 & 44,2 & & & \\
\hline
\end{tabular}


El análisis comparativo por género evidenció que la dificultad permanente para caminar fue la que en mayor porcentaje se presentó en los hombres $(58,5 \%)$, mientras las dificultades para hablar y comunicarse fue seleccionada por el 45,8 \% de las mujeres. Las dificultades para oír, percibir la luz y objetos y personas, y pensar y memorizar tuvieron altos porcentajes de selección en los hombres, mientras que en las mujeres, las dificultades para relacionarse con las demás personas y retener la orina fueron seleccionadas en el 44,6\% de ellas. Se evidenció asociación estadísticamente significativa entre las dificultades permanentes para pensar, retener o expulsar orina y caminar, correr, saltar, siendo la magnitud de la fuerza de asociación nula.

\section{Tabla 29}

Comparativo de la población registrada según las barreras permanentes y el sexo

\begin{tabular}{l|c|c|c|c|c|c|c|c}
\hline \multicolumn{1}{c|}{ Barreras } & Total & Hombres & $\begin{array}{c}\text { \% } \\
\text { Hombres }\end{array}$ & Mujeres & $\begin{array}{c}\text { \% } \\
\text { Mujeres }\end{array}$ & Chi2 & $\begin{array}{c}\text { P } \\
\text { valor }\end{array}$ & Phi \\
\hline Dormitorio & 3615 & 2040 & 90,2 & 1575 & 88,3 & 3,760 & 0,052 & 0,030 \\
Sala & 3683 & 2091 & 92,5 & 1592 & 89,3 & 12,505 & 0,000 & 0,056 \\
Baño & 3176 & 1803 & 79,7 & 1373 & 77 & 4,435 & 0,035 & 0,033 \\
Escalera & 3254 & 1851 & 81,9 & 1403 & 78,7 & 6,408 & 0,011 & 0,040 \\
Pasillo & 3586 & 2032 & 89,9 & 1564 & 83,8 & 4,697 & 0,030 & 0,034 \\
Andén & 3444 & 1949 & 86,2 & 1495 & 83,8 & 4,369 & 0,037 & 0,033 \\
Calle & 2873 & 1644 & 72,7 & 1229 & 68,9 & 6,933 & 0,009 & 0,031 \\
Parque & 3497 & 1992 & 88,1 & 1505 & 84,4 & 11,632 & 0,001 & 0,054 \\
\hline Paradero & 355 & 2007 & 88,8 & 1548 & 86,8 & & & \\
Vehículo & 3227 & 1847 & 81,7 & 1380 & 77,4 & 11,390 & 0,001 & 0,053 \\
\hline Educativo & 3797 & 2132 & 94,3 & 1665 & 93,4 & & & \\
Trabajo & 3871 & 2163 & 95,7 & 1708 & 95,8 & & & \\
\hline Centro salud & 3636 & 2074 & 91,7 & 1521 & 87,6 & 18,692 & 0,000 & 0,068 \\
\hline Centro & 3532 & 2011 & 89 & 1521 & 85,3 & 12,480 & 0,000 & 0,056 \\
comercial & 3810 & 2137 & 94,5 & 1673 & 93,8 & 11,695 & 0,000 & 0,054 \\
\hline Otros & & & & & & & \\
\hline
\end{tabular}


De los sujetos participantes $95,7 \%$ de los hombres percibe barreras en su trabajo que le impide desarrollar sus actividades diarias con mayor autonomía y para el grupo de mujeres esta percepción se evidencia en un 95,8 \%. En el entorno educativo $94,3 \%$ de los hombres dice encontrar barreras y $93,4 \%$ de las mujeres dice hallarlo en este espacio.

En los centros de salud $91,7 \%$ de los hombres encuestados y $87,6 \%$ de las mujeres dice observar barreras; $92,5 \%$ de los hombres y $89,3 \%$ de las mujeres encuestadas dice percibirlas en la sala de sus viviendas; 90,2 \% de los hombres y $88,3 \%$ de las mujeres en el dormitorio. Entre tanto que $94,5 \%$ de los hombres que respondieron la encuesta dicen que las perciben en otros entornos al igual que el 93,8 \% de las mujeres encuestadas. Al realizar la prueba de Chi cuadrado se observa cómo en todas las barreras se encontró asociación estadísticamente significativa con una fuerza de magnitud nula excepto en paradero, centro educativo y centro de salud.

Tabla 30

Comparativo de la población registrada según las consecuencias de la discapacidad y el sexo

\begin{tabular}{|c|c|c|c|c|c|c|c|c|}
\hline $\begin{array}{c}\text { Consecuen- } \\
\text { cias de la } \\
\text { discapacidad }\end{array}$ & Total & Hombres & $\begin{array}{c}\% \\
\text { Hombres }\end{array}$ & Mujeres & $\begin{array}{c}\% \\
\text { Mujeres }\end{array}$ & Chi2 & $\begin{array}{c}\mathbf{P} \\
\text { valor }\end{array}$ & Phi \\
\hline Salud madre & 491 & 288 & 14,9 & 203 & 13,9 & & & \\
\hline Parto & 263 & 154 & 7,9 & 109 & 7,5 & & & \\
\hline Enfermedad & 1066 & 531 & 27,4 & 535 & 36,6 & & & \\
\hline $\begin{array}{l}\text { Alteración } \\
\text { genética }\end{array}$ & 467 & 265 & 13,7 & 202 & 13,8 & & & \\
\hline $\begin{array}{l}\text { Lesión } \\
\text { auto-infligida }\end{array}$ & 32 & 16 & 0,8 & 16 & 1 & & & \\
\hline $\begin{array}{l}\text { Enfermedad } \\
\text { profesional }\end{array}$ & 80 & 61 & 3,1 & 19 & 1,3 & 14,739 & 0,022 & 0,060 \\
\hline Psicoactivo & 28 & 23 & 1,2 & 5 & 0,3 & 13,655 & 0,001 & 0,058 \\
\hline $\begin{array}{l}\text { Desastre } \\
\text { natural }\end{array}$ & 4 & 2 & 0,1 & 2 & 0,1 & & & \\
\hline Accidente & 480 & 303 & 15,6 & 177 & 12,1 & 93,046 & 0,001 & 0,152 \\
\hline Violencia & 79 & 66 & 3,4 & 13 & 0,9 & 40,750 & 0,000 & 0,100 \\
\hline Conflicto & 13 & 13 & 0,7 & 0 & 0 & 23,534 & 0,000 & 0,076 \\
\hline Dificultades & 78 & 44 & 2,3 & 34 & 2,3 & & & \\
\hline Otra causa & 319 & 172 & 8,9 & 147 & 10 & & & \\
\hline
\end{tabular}


El $27,4 \%$ de los hombres considera que su discapacidad fue generada a consecuencia de una enfermedad general mientras que esta consideración se presenta en un 36,6 \% de las mujeres. El 14,9\% de los hombres dice que se debe a las condiciones de salud de su madre, mientras que el $13,9 \%$ también lo considera; otras de las causas seleccionadas por los hombres fueron los accidentes $(15,6 \%)$ y la alteración genética hereditaria $(13,7 \%)$. En cuanto a las mujeres, también seleccionaron en mayor porcentaje la alteración genética hereditaria $(13,8 \%)$ y los accidentes $(12,1 \%)$ como causa de su discapacidad. En menor proporción fueron seleccionadas por los hombres, complicaciones en el parto $(7,9 \%)$ y la violencia $(3,4 \%)$; y las mujeres seleccionaron en menor proporción las complicaciones durante el parto $(7,5 \%)$ y las dificultades en la prestación de salud $(2,3 \%)$. Se evidenció asociación estadísticamente significativa en las consecuencias de la discapacidad de enfermedad profesional, psicoactivo, accidente, violencia y conflicto armado, siendo la magnitud de la fuerza de asociación nula para todas y leve para accidente.

Tabla 31

Comparativo de la población registrada según las alteraciones permanentes y la edad

\begin{tabular}{|c|c|c|c|c|c|c|c|}
\hline \multicolumn{6}{|c|}{ Edad (años) } & \multirow{2}{*}{$\begin{array}{c}\mathbf{P} \\
\text { valor }\end{array}$} & \multirow[b]{2}{*}{ Phi } \\
\hline Alteraciones permanentes & $0-16$ & $17-34$ & $35-64$ & $>65$ & Chi2 & & \\
\hline \multirow{2}{*}{$\begin{array}{l}\text { Sistema } \\
\text { nervioso }\end{array}$} & 301 & 484 & 620 & 235 & \multirow[t]{2}{*}{61249} & \multirow[t]{2}{*}{0,00} & \multirow[t]{2}{*}{0,12} \\
\hline & 43,4 & 46,9 & 40,9 & 29,3 & & & \\
\hline \multirow[t]{2}{*}{ Los ojos } & 157 & 164 & 316 & 326 & \multirow[t]{2}{*}{169,709} & \multirow[t]{2}{*}{0,000} & \multirow[t]{2}{*}{0,20} \\
\hline & 22,7 & 15,9 & 20,8 & 40,7 & & & \\
\hline \multirow[t]{2}{*}{ Los oídos } & 110 & 178 & 187 & 123 & \multirow[t]{2}{*}{13,038} & \multirow[t]{2}{*}{0,005} & \multirow[t]{2}{*}{0,057} \\
\hline & 15,9 & 17,2 & 12,3 & 15,4 & & & \\
\hline \multirow{2}{*}{$\begin{array}{l}\text { Demás } \\
\text { sentidos }\end{array}$} & 36 & 36 & 42 & 26 & \multirow[t]{2}{*}{8,522} & \multirow[t]{2}{*}{0,03} & \multirow[t]{2}{*}{0,046} \\
\hline & 5,2 & 3,5 & 2,8 & 3,2 & & & \\
\hline \multirow{2}{*}{$\begin{array}{l}\text { Voz y } \\
\text { habla }\end{array}$} & 395 & 473 & 415 & 125 & \multirow[t]{2}{*}{$372,506 a$} & \multirow[t]{2}{*}{0,000} & \multirow[t]{2}{*}{0,304} \\
\hline & 57 & 45,8 & 27,4 & 15,6 & & & \\
\hline \multirow{2}{*}{$\begin{array}{l}\text { Sistema cardio- } \\
\text { respiratorio }\end{array}$} & 90 & 67 & 111 & 94 & \multirow[t]{6}{*}{34,140} & \multirow[t]{6}{*}{0,000} & \multirow[t]{6}{*}{0,092} \\
\hline & 13 & 6,5 & 7,3 & 11,7 & & & \\
\hline \multirow[t]{2}{*}{ Digestión } & 50 & 59 & 81 & 40 & & & \\
\hline & 7,2 & 5,7 & 5,3 & 5 & & & \\
\hline \multirow[t]{2}{*}{ Genital } & 26 & 42 & 48 & 43 & & & \\
\hline & 3,8 & 4,1 & 3,2 & 5,4 & & & \\
\hline \multirow[t]{2}{*}{ Movimiento } & 320 & 415 & 820 & 559 & \multirow{4}{*}{171,356} & \multirow[t]{4}{*}{0,000} & \multirow[t]{4}{*}{0,206} \\
\hline & 46,2 & 40,2 & 54,1 & 69,8 & & & \\
\hline \multirow[t]{2}{*}{ Piel } & 26 & 40 & 66 & 36 & & & \\
\hline & 3,8 & 3,9 & 4,4 & 4,5 & & & \\
\hline
\end{tabular}


La tabla anterior muestra cómo al comparar la edad con las alteraciones permanentes, en el rango de edad de 0 hasta 24 años en mayor porcentaje se encuentran las alteraciones permanentes de los demás órganos de los sentidos, la digestión, el metabolismo y las hormonas, el sistema genital y reproductivo, el sistema cardiorrespiratorio y la piel; entre 17 y 34 años sobresalen las alteraciones de digestión, sistema genital y reproductivo y piel; a partir de los 45 años sobresalen los oídos, demás órganos de los sentidos y el sistema cardiorrespiratorio. Se evidencia que existe asociación estadísticamente significativa entre las alteraciones permanentes del sistema nervioso, los ojos, los oídos, demás sentidos, voz y habla, sistema cardiorrespiratorio, y el movimiento. La magnitud de la fuerza de asociación es moderada para el movimiento, los ojos y la voz y el habla.

Tabla 32

Comparativo de la población registrada según las dificultades y la edad

\begin{tabular}{|c|c|c|c|c|c|c|c|}
\hline \multicolumn{8}{|c|}{ Edad (años) } \\
\hline Dificultades permanentes & $0-16$ & $17-34$ & $35-64$ & $>65$ & Chi2 & $\begin{array}{c}\mathbf{P} \\
\text { valor }\end{array}$ & Phi \\
\hline \multirow[t]{2}{*}{ Para pensar } & 280 & 427 & 500 & 197 & \multirow[t]{2}{*}{68,138} & \multirow[t]{2}{*}{0,000} & \multirow[t]{2}{*}{0,130} \\
\hline & 40,4 & 41,3 & 33 & 24,6 & & & \\
\hline \multirow{2}{*}{$\begin{array}{l}\text { Percibir la luz, } \\
\text { distinguir objetos }\end{array}$} & 87 & 92 & 184 & 224 & \multirow[t]{2}{*}{152,076} & \multirow[t]{2}{*}{0,000} & \multirow[t]{2}{*}{0,194} \\
\hline & 12,6 & 8,9 & 12,1 & 28 & & & \\
\hline \multirow{2}{*}{$\begin{array}{l}\text { Oír aun con } \\
\text { aparatos especiales }\end{array}$} & 68 & 100 & 104 & 63 & \multirow[t]{2}{*}{9,041} & \multirow[t]{2}{*}{0,029} & \multirow[t]{2}{*}{0,047} \\
\hline & 9,8 & 9,7 & 6,9 & 7,9 & & & \\
\hline \multirow{2}{*}{$\begin{array}{l}\text { Distinguir sabores } \\
\text { u olores }\end{array}$} & 39 & 40 & 40 & 20 & \multirow[t]{2}{*}{16,670} & \multirow[t]{2}{*}{0,001} & \multirow[t]{2}{*}{0,062} \\
\hline & 5,6 & 3,9 & 2,6 & 2,5 & & & \\
\hline \multirow[t]{2}{*}{ Hablar y comunicarse } & 393 & 462 & 436 & 122 & \multirow[t]{2}{*}{350,500} & \multirow[t]{2}{*}{0,000} & \multirow[t]{2}{*}{0,294} \\
\hline & 56,7 & 44,7 & 28,7 & 15,2 & & & \\
\hline \multirow{2}{*}{$\begin{array}{l}\text { Desplazarse en } \\
\text { trechos cortos }\end{array}$} & 62 & 66 & 131 & 142 & \multirow[t]{2}{*}{72,620} & \multirow[t]{2}{*}{0,000} & \multirow[t]{2}{*}{0,0134} \\
\hline & 8,9 & 6,4 & 8,6 & 17,7 & & & \\
\hline
\end{tabular}




\begin{tabular}{|c|c|c|c|c|c|c|c|}
\hline \multicolumn{8}{|c|}{ Edad (años) } \\
\hline Dificultades permanentes & $0-16$ & $17-34$ & $35-64$ & $>65$ & Chi2 & $\begin{array}{c}\mathbf{P} \\
\text { valor }\end{array}$ & Phi \\
\hline \multirow{2}{*}{$\begin{array}{l}\text { Masticar tragar, } \\
\text { asimilar }\end{array}$} & 85 & 75 & 62 & 53 & \multirow[t]{2}{*}{50,669} & \multirow[t]{2}{*}{0,000} & \multirow[t]{2}{*}{0,112} \\
\hline & 12,3 & 7,3 & 4,1 & 6,6 & & & \\
\hline \multirow{2}{*}{$\begin{array}{l}\text { Retener o expulsar } \\
\text { la orina }\end{array}$} & 55 & 79 & 125 & 98 & \multirow[t]{2}{*}{14,674} & \multirow[t]{2}{*}{0,002} & \multirow[t]{2}{*}{0,060} \\
\hline & 7,9 & 7,6 & 8,2 & 12,2 & & & \\
\hline \multirow[t]{2}{*}{ Caminar, correr, saltar } & 288 & 397 & 751 & 523 & \multirow[t]{4}{*}{146,352} & \multirow[t]{4}{*}{0,000} & \multirow[t]{4}{*}{0,190} \\
\hline & 41,6 & 38,4 & 49,5 & 65,3 & & & \\
\hline \multirow{2}{*}{$\begin{array}{l}\text { Mantener piel, uñas } \\
\text { y cabellos }\end{array}$} & 39 & 55 & 74 & 39 & & & \\
\hline & 5,6 & 5,3 & 4,9 & 4,9 & & & \\
\hline \multirow{2}{*}{$\begin{array}{l}\text { Relacionarse con } \\
\text { las demás personas }\end{array}$} & 113 & 194 & 202 & 68 & \multirow[t]{2}{*}{42,538} & \multirow[t]{2}{*}{0,000} & \multirow[t]{2}{*}{0,103} \\
\hline & 16,3 & 18,8 & 13,3 & 8,5 & & & \\
\hline \multirow{2}{*}{$\begin{array}{l}\text { Llevar, mover, utilizar } \\
\text { objetos }\end{array}$} & 126 & 159 & 229 & 179 & \multirow[t]{2}{*}{22,512} & \multirow[t]{2}{*}{0,000} & \multirow[t]{2}{*}{0,075} \\
\hline & 18,2 & 15,4 & 15,1 & 22,3 & & & \\
\hline \multirow{2}{*}{$\begin{array}{l}\text { Cambiar y mantener } \\
\text { posiciones }\end{array}$} & 116 & 154 & 241 & 200 & \multirow[t]{2}{*}{38,608} & \multirow[t]{2}{*}{0,000} & \multirow[t]{2}{*}{0,098} \\
\hline & 16,7 & 14,9 & 15,9 & 25 & & & \\
\hline \multirow{2}{*}{$\begin{array}{l}\text { Alimentarse, asearse } \\
\text { y vestirse }\end{array}$} & 187 & 186 & 200 & 205 & \multirow[t]{4}{*}{84,378} & \multirow[t]{4}{*}{0,000} & \multirow[t]{4}{*}{0,144} \\
\hline & 27 & 18 & 13,2 & 25,6 & & & \\
\hline \multirow[t]{2}{*}{ Otra } & 31 & 36 & 47 & 32 & & & \\
\hline & 4,5 & 3,5 & 3,1 & 4 & & & \\
\hline
\end{tabular}

Al comparar las dificultades permanentes y la edad se observa que en todas las edades se presentan en mayor porcentaje dificultades para pensar, hablar y comunicarse, caminar, correr y saltar, y oír aun con aparatos especiales. Se evidencia además que excepto en las dificultades de mantener piel, uñas y cabellos y otros no se encontró asociación estadísticamente significativa. La magnitud de la fuerza de asociación para hablar y comunicarse es leve. 
Caracterización de la discapacidad en el distrito de Barranquilla

Tabla 33

Comparativo de la población registrada según las barreras y la edad

\begin{tabular}{|c|c|c|c|c|c|c|c|}
\hline \multicolumn{8}{|c|}{ Edad (años) } \\
\hline Barreras & $0-16$ & $17-34$ & $35-64$ & $>65$ & Chi2 & $\begin{array}{c}\mathbf{P} \\
\text { valor }\end{array}$ & Phi \\
\hline \multirow[t]{2}{*}{ Dormitorio } & 81 & 83 & 144 & 121 & \multirow[t]{2}{*}{27,147} & \multirow[t]{2}{*}{0,000} & \multirow[t]{2}{*}{0,082} \\
\hline & 11,7 & 8 & 9,5 & 15,1 & & & \\
\hline \multirow[t]{2}{*}{ Sala } & 72 & 59 & 111 & 119 & \multirow[t]{2}{*}{54,437} & \multirow[t]{2}{*}{0,000} & \multirow[t]{2}{*}{0,116} \\
\hline & 10,4 & 5,7 & 7,3 & 14,9 & & & \\
\hline \multirow[t]{2}{*}{ Baño } & 133 & 181 & 271 & 283 & \multirow[t]{2}{*}{114,679} & \multirow[t]{2}{*}{0,000} & \multirow[t]{2}{*}{0,168} \\
\hline & 19,2 & 17,5 & 17,9 & 35,3 & & & \\
\hline \multirow[t]{2}{*}{ Escalera } & 93 & 150 & 300 & 247 & \multirow[t]{2}{*}{98,149} & \multirow[t]{2}{*}{0,000} & \multirow[t]{2}{*}{0,156} \\
\hline & 13,4 & 14,5 & 19,8 & 30,8 & & & \\
\hline \multirow[t]{2}{*}{ Pasillo } & 67 & 71 & 145 & 165 & \multirow[t]{2}{*}{97,208} & \multirow[t]{2}{*}{0,000} & \multirow[t]{2}{*}{0,155} \\
\hline & 9,7 & 6,9 & 9,6 & 20,6 & & & \\
\hline \multirow[t]{2}{*}{ Andén } & 75 & 116 & 225 & 184 & \multirow[t]{2}{*}{61,424} & \multirow[t]{2}{*}{0,000} & \multirow[t]{2}{*}{0,123} \\
\hline & 10,8 & 11,2 & 14,8 & 23 & & & \\
\hline \multirow[t]{2}{*}{ Calle } & 169 & 269 & 426 & 307 & \multirow[t]{2}{*}{46,058} & \multirow[t]{2}{*}{0,000} & \multirow[t]{2}{*}{0,107} \\
\hline & 24,4 & 26 & 28,1 & 38,3 & & & \\
\hline Parque & 87 & 125 & 185 & 150 & 23,173 & 0,000 & 0,076 \\
\hline & 12,6 & 12,1 & 12,2 & 18,7 & & & \\
\hline Paradero & 61 & 109 & 186 & 133 & 24,744 & 0,000 & 0,078 \\
\hline & 8,8 & 10,6 & 12,3 & 16,6 & & & \\
\hline Vehículo & 95 & 191 & 329 & 202 & 34,584 & 0,000 & 0,092 \\
\hline & 13,7 & 18,5 & 21,7 & 25,2 & & & \\
\hline Educativo & 76 & 65 & 68 & 38 & 48,177 & 0,000 & 0,097 \\
\hline & 11 & 6,3 & 4,5 & 4,7 & & & \\
\hline Trabajo & 15 & 42 & 75 & 41 & 10,698 & 0,015 & 0,051 \\
\hline & 2,2 & 4,1 & 4,9 & 5,1 & & & \\
\hline Centro salud & 51 & 95 & 136 & 126 & 36,814 & 0,000 & 0,095 \\
\hline & 7,4 & 9,2 & 9 & 15,7 & & & \\
\hline Centro comercial & 72 & 127 & 188 & 123 & 8,725 & 0,033 & 0,046 \\
\hline & 10,4 & 12,3 & 12,4 & 15,4 & & & \\
\hline Otros & 34 & 62 & 62 & 82 & & & \\
\hline & 4,9 & 4,9 & 6 & 5,4 & & & \\
\hline
\end{tabular}


En cuanto al comparativo entre las barreras y la edad de los participantes se encontró que en mayores porcentajes las mayores barreras se establecen en las personas mayores de 65 años. Se evidencia asociación estadísticamente significativa en todas las barreras y la edad, siendo el baño, la sala, las escaleras, el pasillo las que muestran una magnitud de fuerza leve.

La condición de salud está determinada por la edad, el ingreso, el nivel educativo, la actividad laboral, la ubicación geográfica, el género, los hábitos de las personas, y la seguridad social en salud, encontrando que el mayor efecto marginal corresponde al determinante social de la salud; a medida que aumenta el nivel educativo de los individuos, también aumenta la probabilidad de percibir un muy buen estado de salud evidenciando hacia una relación positiva con el estado de salud (36).

En el análisis del género frente a los componentes de la discapacidad, se encontró asociación significativa en algunas de las alteraciones permanentes, las dificultades y las barreras dado que tanto los hombres como las mujeres pueden presentar limitaciones en la actividad, situación que se evidencia en el estudio de la Discapacidad en Chile, donde se presenta que las mujeres tienen mayor porcentaje de limitaciones en las actividades (33).

Como se mencionó anteriormente, las alteraciones o deficiencias permanentes influyen en el desempeño de las actividades cotidianas; actividades como caminar (principalmente), correr y saltar son fundamentales para ejecutar diversas actividades en nuestro diario vivir. La diferencia radica en la forma como se realizan esas actividades diarias: según el concepto de discapacidad de la Organización Mundial de la Salud, si se ejecuta una actividad de manera distinta a lo que se considera normal para el ser humano, ello significaría que la persona cuenta con discapacidad. Nótese cómo en la presente investigación el caminar, correr y saltar representan la limitación más frecuente. 
La etnia, como factor personal $(37,38)$ se clasifica dentro de aquellas circunstancias de construcción social y es factor de exclusión, influye en las desigualdades de salud, así como el género (39).

La presencia de discapacidad en el género está ligada a dos características para tener en cuenta: la edad de la persona y la esperanza de vida al nacer de cada país y región. De acuerdo con la información brindada por el Departamento Nacional de Estadística (DANE), la esperanza de vida en Colombia para el quinquenio 2010- 2015 es de 78 años para las mujeres y 72 para los hombres (40), lo cual está relacionado con los datos de los diversos estudios interpretados anteriormente. El género como determinante social de salud es fundamental porque es una de las principales características que permite identificar la presencia de inequidad social en una población, especialmente en la población con discapacidad.

En los componentes de la discapacidad de acuerdo a la CIF (41), se evidenció que las personas que tienen alguna deficiencia no necesariamente tienen alguna limitación o restricción en la participación, de ahí la importancia de caracterizar a cada individuo en términos de funcionamiento para poder establecer un plan de tratamiento en cuanto a rehabilitación o habilitación. Esto guarda relación con lo expuesto: "los niveles de funcionamiento varían enormemente dentro de una población, ya sea en relación con las capacidades físicas, intelectuales, habilidades sensoriales, o como resultado del impacto de la salud mental. Si estas diferencias no se toman en cuenta se puede limitar seriamente la efectividad de los programas diseñados para promover el bienestar económico y social" (42).

Esto también es coherente con la CIF, que describe claramente que las deficiencias están relacionadas con la discapacidad pero no son determinantes de la misma, es decir, que tener deficiencias no quiere decir que se tiene discapacidad (41). 
De acuerdo con lo que refiere la CIF en relación con la expresión "Discapacitados sociales", para destacar la dificultad de participación que tienen ciertas personas debido a condiciones socioculturales, también se utiliza en aquellos casos en que por diversas circunstancias como pobreza, violencia, producen daños a problemas de salud que llevan a la discapacidad (43).

Similares resultados se encontraron en el estudio donde se muestra que a pesar de ser solo para población infantil y una patología específica también se ve fuertemente influenciado por los determinantes sociales como son área de residencia, afiliación y acceso a los servicios de salud, estrato socioeconómico, los cuales son factores determinantes de la presencia o no de la enfermedad, los determinantes sociales como género, condiciones de vivienda, asistencia a programas de crecimiento y desarrollo no están asociados significativamente a la presencia de enfermedad (42).

Según la CELAP (44), en la gran mayoría de los países, las tasas de discapacidad de los hombres superan a las de las mujeres desde su nacimiento hasta los 40 años, situación que cambia en el siguiente ciclo de vida. Al llegar al grupo de 60 años y más, la prevalencia de las mujeres sobrepasa la de los hombres en todos los países del Caribe y en 11 de los 17 países de América Latina de los que se tienen datos. Contrario a esto, en los resultados de la ciudad de Barranquilla la discapacidad se presenta en mayores de 60 años y con mayor frecuencia en mujeres. Este cambio de patrón, se podría explicar por el hecho de que la mayor esperanza de vida de las mujeres aumenta la posibilidad de tener una discapacidad generada por un accidente o una enfermedad crónica (45).

\section{CONCLUSIONES}

Los resultados del presente estudio muestran cómo las inequidades sociales están presentes de igual manera en los participantes en el estudio; es 
así como el sexo femenino está expuesto a factores de riesgo relacionados con el hogar, dadas las características y las condiciones de la vivienda; además, están más propensas a enfermedades de transmisión sexual, con consecuencias graves para el sexo masculino. Para Barranquilla se reporta que del total de la población con discapacidad la relación hombre: mujer resulta ser similar y las mujeres son las que se ven más afectadas en cuanto a condiciones de salud, al igual que quienes carecen de un ingreso mensual.

El estudio describe que la mayor proporción de personas identificadas con discapacidad reside en la cabecera municipal, en el suroccidente del Distrito y están categorizados en estrato 1 . Se evidenció que la mayor distribución por sexo fue de hombres, la edad con más predominio fue del grupo entre 30 y 34 años, y de las personas registradas según las costumbres y tradiciones, la mayoría se considera mestizo u otro diferente. La mayoría tiene afiliación al régimen subsidiado.

Se observó que las personas caracterizadas con discapacidad en su mayoría residen en vivienda propia y cuentan con servicios públicos: energía eléctrica, acueducto, alcantarillado, gas natural, recolección de basuras y servicio telefónico, un inferior porcentaje no cuenta con servicios básicos. En su mayoría viven acompañados, la mayor proporción tienen a cargo otra persona y no reciben algún servicio del Instituto Colombiano de Bienestar Familiar, ni son beneficiarios de alguno de los programas que ellos ofrecen.

Con relación a las alteraciones permanentes presentes en las personas encuestadas, se observó que la mayoría tiene alteración permanente de los órganos de los sentidos (gusto, olfato y tacto); de las dificultades permanentes más frecuentes se evidenció la dificultad para distinguir sabores $\mathrm{u}$ olores como la más predominante. La mayoría de las personas tiene conocimiento del origen de su discapacidad y en mayor proporción indicó que se debió como consecuencia de una enfermedad clasificada como general, 
seguido de una condición de salud de la madre durante el embarazo, y otro menor porcentaje debido a un accidente. Un porcentaje considerable afirmó que se debió a una enfermedad profesional generada por carga de trabajo físico o mental, específicamente por factores ergonómicos; con relación al consumo de sustancias psicoactivas, en mayor proporción indicaron que su discapacidad se debió a consumo de psicoactivos no aceptados socialmente. Otro porcentaje indicó que fue a consecuencia de un desastre natural, otro grupo consideró que fue a causa de un accidente en el hogar, y otro porcentaje, que es el resultado del conflicto armado por arma de fuego, seguido por minas antipersonas.

Por otra parte, se concluye que las personas con discapacidad afirman que no perciben actitud negativa en las personas que les rodean, que lleve a dificultarles su autonomía. Con relación a las barreras, las personas perciben que es en el trabajo donde con mayor frecuencia tienen barreras que les impiden desarrollar sus actividades diarias con autonomía, seguido de otros lugares diferentes a los del listado descrito en la encuesta. Relacionado con las TIC y los medios de comunicación, la población participante en este estudio, indicó que utilizan el Internet y los medios de comunicación escritos para mantenerse enterados de lo que sucede en el medio.

Lo realizado en el distrito de Barranquilla da respuesta a lo que en el mundo y especialmente en Latinoamérica se viene desarrollando; aunque son diferentes las fuentes de datos sobre personas con discapacidad con las que cuentan los organismos oficiales, a partir del presente siglo se ha contado con censos de población, encuestas de hogares, encuestas especiales sobre personas con discapacidad y registros continuos que le permiten a los gobiernos identificar las características de la población con discapacidad que la cual cuenta su región ya que ello -relacionado con variables sociodemográficas y económicas- favorece la comprensión global de la situación 
facilitando la planificación de las medidas de prevención, asistencia, rehabilitación y creación de servicios en todos los niveles.

Con este estudio se favoreció la elaboración de un diagnóstico que permitiera conocer la distribución de la discapacidad en la población en términos de las limitaciones, etiología, severidad, distribución sociodemográfica, condición laboral, del proceso de atención en rehabilitación, aspectos relacionados con la salud, así como la educación. Estos resultados además, se constituyen en la base para la realización de estudios de intervención y el diseño de políticas que favorezcan la inclusión de las personas con discapacidad de manera integral en escenarios productivos, de la vida ciudadana y cultural principalmente ya que son donde menos participación tienen.

Al relacionar las alteraciones permanentes con el sexo y la edad se evidenció cómo las alteraciones del sistema nervioso, de la voz y el habla, genitales y del movimiento del cuerpo, manos, brazos y piernas, las dificultades permanentes para caminar, hablar y comunicarse se presentan en mayor porcentaje en los hombres, siendo igualmente en mayor porcentaje en los sujetos ente 17 y 34 años.

Las barreras percibidas en el trabajo que impiden realizar sus actividades diarias es mayor en los hombres, de igual forma esta percepción de barreras es en escenarios como los centros de salud, en las salas de sus viviendas, en los dormitorios, en la calle y otros entornos, y son los adultos mayores quienes en mayor porcentaje establecen estas barreras.

Se evidenció que las personas que tienen alguna deficiencia no necesariamente tienen alguna limitación o restricción en la participación, de ahí la importancia de caracterizar a cada individuo en términos de funcionamiento para poder establecer un plan de tratamiento en cuanto a rehabilitación o habilitación. 


\section{REFERENCIAS BIBLIOGRÁFICAS}

1. Morales MS, Arboleda AO, González CP. Análisis demográfico de Colombia 2005-2010: una lectura en clave de política pública en salud. Revista CES Salud Pública. 2(2):110-124.

2. Neves SP, Álvarez EM. Estudio descriptivo de las características sociodemográficas de la discapacidad en América Latina. Ciência \& Saúde Coletiva. 2014; 19(12):4889-4898.

3. Ministerio de Salud y Protección Social. Dirección de Epidemiología y Demografía Grupo ASIS. Análisis de situación de salud de poblaciones diferenciales relevantes. 2013. En: https://www.minsalud.gov. co/Documentos\%20y\%20Publicaciones/An\%C3\%A1lisis\%20de \%20 poblaciones\%20diferenciales.pdf

4. Organización Panamericana de la Salud. Universidad Nacional Autónoma de Honduras. Situación mundial de la discapacidad. 2013 En: http://www.bvs.hn/Honduras/Discapacidad/Docentes/Situacion\%20 Mundial\%20de\%201a\%20Discapacidad.pdf

5. Lugo AL, Seijas V. La discapacidad en Colombia: una mirada global. Rev Col Med Fis Rehab. 2012; 22(2):164-179.

6. Fresnillo PM. Desde la familia, la discapacidad se mira con otros ojos. Revista Educación y futuro digital. 2014; 60-73.

7. Ministerio de Salud y Protección Social. Oficina de Promoción Social. Sala Situacional de Personas con Discapacidad, Nacional. Octubre 2016. En: https://www.minsalud.gov.co/sites/rid/Lists/BibliotecaDigital/RIDE/DE/PS/sala-situacional-discapacidad-nacional-oct-2016.pdf

8. Hurtado FM, Aguilar ZJ, Mora AA, Sandoval JC, Peña SC, León DA. Identificación de las barreras del entorno que afectan la inclusión social de la persona con discapacidad motriz de miembros inferiores. Salud Uninorte. Barranquilla (Col.). 2012; 28(2):227-237.

9. González SP, Astudillo ME, Hurtado LE. Salud mental positiva y apoyo social percibido en personas con discapacidad física. Revista Cultura del ciudadano. 2012; 9(2):39-49. 
10. Vélez AC, Vidarte CJ, Cerón BJ. Determinantes sociales de la salud y discapacidad: caso Santiago de Cali. Rev. Fac. Nac. Salud Pública. 31(1):192-202.

11. Huiracocha TL, Almeida AC, Huiracocha TK, Arteaga HA, Arteaga AJ, Barahona HP, Quezada HJ. Explorando los sentimientos de los padres, la familia y la sociedad a las personas con Síndrome de Down: Estudio observacional. MASKANA. 2013; 4(2):47-57.

12. Araya CA, González AM, Cerpa RC. Actitud de universitarios hacia las personas con discapacidad. Educación y Educadores. 2014; 17(2):289-305.

13. Serrano RC, Ramírez RC, Abril MJ, Ramón CL, Guerra UL, Clavijo GN. Barreras contextuales para la participación de las personas con discapacidad física. Salud UIS. 2013; 45(1):41-45.

14. Martínez BC, Silva SR, Naranjo GB. Accesibilidad a la información y la inclusión social de personas con discapacidad visual. MASKANA. 2017; 8(1):79-86.

15. García PD, San Martín PP. Caracterización sociodemográfica y clínica de la población atendida en el Instituto Teletón de Santiago. Rev ChilPediatr. 2015; 86(3):161-167.

16. Ministerio de Salud y Protección Social. Análisis de situación de Salud. Colombia. 2014. Bogotá, D. C.; 2014.

17. Organización Mundial de la Salud. Informe Mundial de Discapacidad, 2011. Génova; 2011.

18. Revilla AH, González MD, Valenzuela FL. Calidad de la atención de salud brindada en un servicio de rehabilitación integral de base comunitaria. MEDISAN. 2016; 20(3):313-319.

19. Organización Mundial de la Salud. Guía para la rehabilitación basada en la comunidad. Ginebra. 2012.

20. Mortenson WB, Demers L, Fuhrer MJ, Jutai JW, Lenker J, DeRuyter F. Effects of an assistive technology intervention on older adults with 
disabilities and their informal caregivers: an exploratory randomized controlled trial. Am J Phys Med Rehabil. 2013; 92(4):297-306.

21. Mactaggart I, Kuper H, Murthy GV, Sagar J, Oye J, Polack S. Assessing health and rehabilitation needs of people with disabilities in $\mathrm{Ca}-$ meroon and India. Disabil Rehabil. 2016; 38(18):1757-1764.

22. Gudlavalleti MV, John N, Allagh K, Sagar J, Kamalakannan S, Ramachandra SS, et al. Access to health care and employment status of people with disabilities in South India, the SIDE (South India Disability Evidence) study. BMC Public Health. 2014; 14(1125):1-8.

23. Webster BS, Verma S, Willetts J, Hopcia K, Wasiak R. Association of disability duration with physical therapy services provided after meniscal surgery in a workers' compensation population. Arch Phys Med Rehabil. 2011; 92(10):1542-1551.

24. Hernández JJ, Hernández UI. Una aproximación a los costos indirectos de la discapacidad en Colombia. Rev. Salud Pública. 2005; 7(2):130-144.

25. Organización Mundial de la Salud. Organización Panamericana de la Salud. Romper las barreras y abrir las puertas: Discapacidad y Desarrollo. New York. 2013.

26. República de Colombia. Decreto 2309 de 2002. Sistema Obligatorio de Garantía de Calidad de la Atención de Salud del Sistema General de Seguridad Social en Salud. Bogotá. 2002.

27. Restrepo C J. La calidad en la prestación de los servicios de salud: un imperativo por lograr. Rev. Fac. Nac. Salud Pública. 2007; 25(1):78-81.

28. Rubio MM. Equidad en el Acceso a los Servicios de Salud y Equidad en la Financiación de la Atención en Bogotá. Rev. Salud Pública. 2008; 10(1):29-43.

29. Herazo BY, Domínguez AR. Correlación entre pobreza extrema y discapacidad en los Departamentos de Colombia. Cienc. innov. salud. 2013; 1(1):11-17. 
30. Hurtado LL, Agudelo MM. Inclusión educativa de las personas con discapacidad en Colombia CES Movimiento y Salud. 2014; 2(1):45-55.

31. Padilla MA. Inclusión educativa de personas con discapacidad. Rev. Colomb. Psiquiat. 2011; 40(4):670-699.

32. Cabrales GM, Navarro K, Villanueva C, Coronel L. Impacto dela discapacidad en la vereda los Tres del municipio de Los Santos, Santander 2012. Rev. Fac. Cienc. Salud UDES (Bucaramanga). 2014; 1(2):101-106.

33. Organización Mundial de la Salud. Informe mundial sobre la violencia y la salud. Washington DC; 2002.

34. Velez C, Vidarte JA. Discapacidad y Determinantes Sociales de la Salud Estructurales e Intermedios: Diferencias por Género. Cienc. innov. salud. 2014; 2(2):63-69.

35. Borrell C, Rodríguez M, Pérez G, García AA. Las desigualdades sociales en salud en el Estado español. Aten Primaria. 2008; 40(2):59-60.

36. Tovar L. Determinantes del estado de salud de la población colombiana. Econ. Gest. Desarro. 2005; 3:125-151.

37. Weber LA. Conceptual framework forunder standingrace, class, gender and sexuality. Psychology of Women Quarterly. 1998; 22:13-32.

38. Weber LA. Reconstructing the landscape of health disparities research. Promoting dialogue and collaboration between feminism intersectional and biomedical paradigms. In: Schulz AJ, Mullings L, editores. Gender, race, class, and health. Intersectional approaches. San Francisco: Jossey- Bass; 2006, pp. 21-59.

39. Astorga LF. Incluyendo a las personas con discapacidad en las políticas de desarrollo. Managua, Nicaragua, 2007. p.3.

40. Departamento Administrativo Nacional de Estadística (DANE). Comunicado de prensa Estudios demográficos del DANE. Bogotá D.C.: Departamento Administrativo Nacional de Estadística; 2005.

41. Weber L.A. Reconstructing the landscape of health disparities re- 
search. Promoting dialogue and collaboration between feminist intersectional and biomedical paradigms. In: Schulz AJ, Mullings L, editores. Gender, race, class, and health. Intersectional approaches. San Francisco: Jossey-Bass; 2006. 21-59.

42. Sen A. Inequality reexamined. Cambridge, MA: Harvard University Press, y Oxford Clarendon Press; 1992. 2-9

43. Organización Mundial de la Salud. Lograr la equidad en salud: desde las causas iniciales a los resultados justos. declaración provisional. Ginebra: Comisión sobre Determinantes Sociales de la Salud; 2007. En whqlibdoc.who.int/publications/2007/interim_statement_spa.pdf

44. Gómez JC. Discapacidad en Colombia: Reto para la inclusión en Capital Humano. Bogotá: Fundación Saldarriaga Concha; 2010. 28-37.

45. Naciones Unidas. Objetivos del Milenio informe de 2011. New York: Naciones Unidas; 2011. En: http://www.un.org/es/millenniumgoals/ pdf/11-31342(S)MDG_Report_2011_Book_LR.pdf

\footnotetext{
Cómo citar este capítulo:

Herazo Beltrán YPPY, Vidarte Claros JA. (2018). Metodología, resultados y discusión basado en el estudio “Caracterización y localización de las personas en situación de discapacidad en el distrito de Barranquilla. In Pinillos Patiño Y, Herazo Beltrán Y, Vidarte Claros JA, Crissién Quiroz EM, Suárez Palacio D, García Puello F, et al. Caracterización de la discapacidad en el distrito de Barranquilla. Una mirada conceptual y experiencial. Barranquilla: Universidad Simón Bolívar, p. 229-293.
} 